\title{
HIV/AIDS vulnerabilities, discrimination, and service accessibility among Africa's youth: Insights from a multi-country study
}

\author{
Babatunde A.O. Ahonsi \\ Population Council \\ Nahla G. Abdel-Tawab \\ Population Council \\ Scott Geibel \\ Population Council \\ Sam Kalibala \\ Population Council \\ Jerry Okal \\ Population Council
}

See next page for additional authors

Follow this and additional works at: https://knowledgecommons.popcouncil.org/departments_sbsr-hiv

Part of the Demography, Population, and Ecology Commons, Family, Life Course, and Society

Commons, International Public Health Commons, and the Maternal and Child Health Commons

How does access to this work benefit you? Let us know!

\section{Recommended Citation}

Ahonsi, Babatunde A. O. , Nahla G. Abdel-Tawab, Scott Geibel, Sam Kalibala, Jerry Okal, Babacar Mane, Nathi Sohaba, Julialynne Walker, and Eric P. Green. 2014. "HIV/AIDS vulnerabilities, discrimination, and service accessibility among Africa's youth: Insights from a multi-country study." Abuja: Population Council. 


\section{Authors}

Babatunde A.O. Ahonsi, Nahla G. Abdel-Tawab, Scott Geibel, Sam Kalibala, Jerry Okal, Babacar Mane, Nathi Sohaba, Julialynne Walker, and Eric P. Green 


\section{HIV/AIDS VULNERABILITIES, DISCRIMINATION, AND SERVICE ACCESSIBILITY AMONG AFRICA'S YOUTH}

INSIGHTS FROM A MULTI-COUNTRY STUDY

Babatunde Ahonsi

Nahla Tawab Scott Geibel

Sam Kalibala Jerry Okal Babacar Mane Nathi Sohaba Julialynne Walker

Eric Green 
Ideas. Evidence. Impact.

The Population Council confronts critical health and development issues-from stopping the spread of HIV to improving reproductive health and ensuring that young people lead full and productive lives. Through biomedical, social science, and public health research in 50 countries, we work with our partners to deliver solutions that lead to more effective policies, programs, and technologies that improve lives around the world. Established in 1952 and headquartered in New York, the Council is a nongovernmental, nonprofit organization governed by an international board of trustees.

Population Council

No. 16 Mafemi Crescent

Abuja

Nigeria

Tel: +234 $98706071 ;+23498706057 ;+2348067787750$

email: info.nigeria@popcouncil.org

popcouncil.org

Suggested citation: Ahonsi, Babatunde, Nahla Tawab, Scott Geibel, Sam Kalibala, Jerry Okal, Babacar Mane, Nathi Sohaba, Julialynne Walker, and Eric Green. 2014. "HIV/AIDS vulnerabilities, discrimination, and service accessibility among Africa's youth: Insights from a multi-country study." Abuja: Population Council.

\section{Acknowledgments}

This publication is based on research funded by the Ford Foundation and conducted by the Population Council. Our team of investigators was instrumental in the research process. Most especially, we thank the key informants and youth who graciously gave their time and shared insights and intimate details of their experiences as participants in the research. This study is dedicated to them and to the goal of HIV prevention and impact mitigation among youth in Africa and beyond.

\section{Study Team}

\section{Research Team}

Babatunde Ahonsi (Nigeria)

Nahla Tawab (Egypt)

Scott Geibel and Sam Kalibala (Kenya)

Jerry Okal (Uganda)

Babacar Mane (Senegal)

Nathi Sohaba and Julialynne Walker (South Africa)

Eric Green (United States)
Research Support Team

Nigeria:

Ayo Oginni

Otibho Obianwu

George Eluwa

Sylvia Adebajo

New York:

Michelle Chau

Marie Stoner 


\section{Table of Contents}

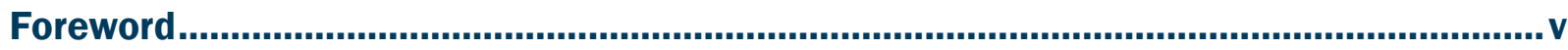

Abbreviations/Acronyms ........................................................................................... vi

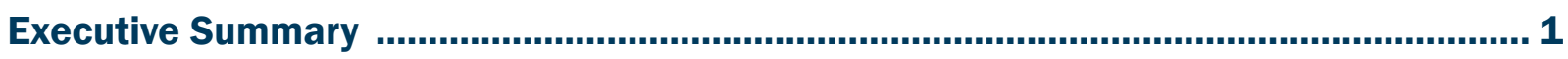

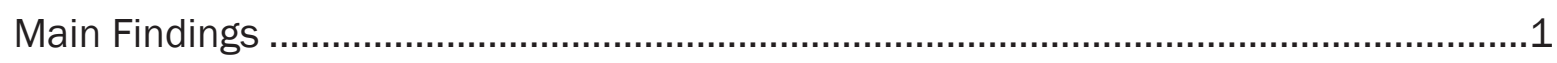

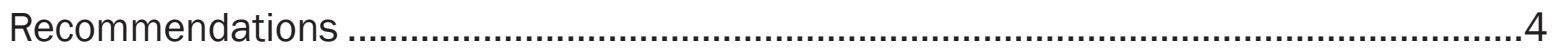

Chapter 1 Background ............................................................................................... 6

Chapter 2 Methods and Data Sources ................................................................................ 9

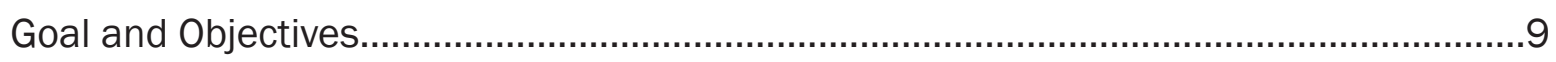

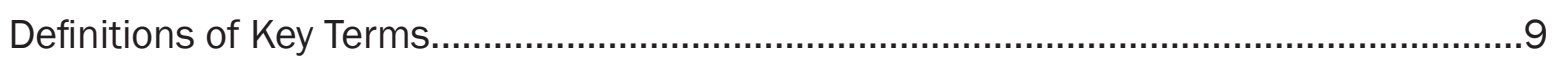

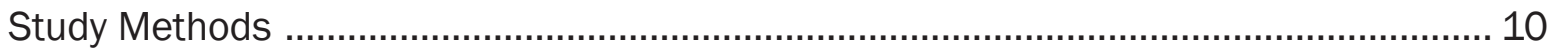

Instrument Development and Analysis .................................................................. 13

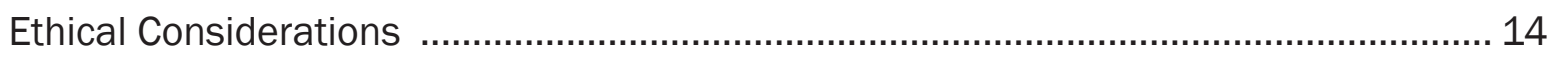

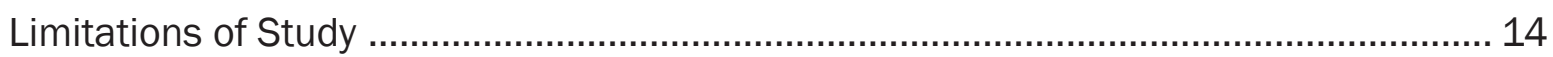

Chapter 3 Legal and Policy Issues in Youth Vulnerabilities to HIV and Sexual

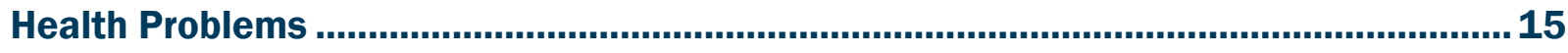

Responsiveness of National Laws and Policies: Commonalities and Divergences ........ 15

Youth Focus in Policies and Program Strategies ......................................................... 17

Legally Based Manifestations of HIV-related Stigma and Discrimination ..................... 19

Chapter 4 Patterns in Sexual Behaviors and HIV-Related Discrimination..................... 21

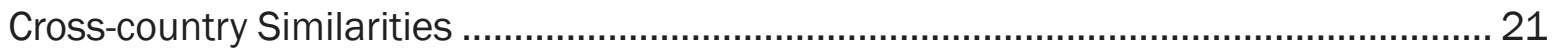

Factors in the Sexual-Risk and Health-seeking Behaviors of Youth ............................... 27

Chapter 5 HIV Youth-Focused Responses at the Individual, Institutional, and

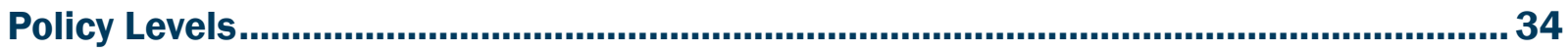

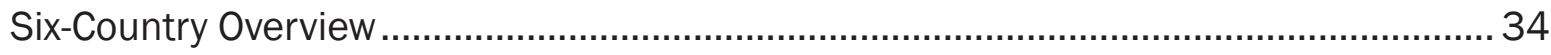

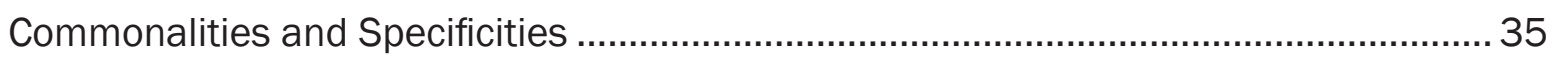

Youth Involvement in Program Implementation and Service Delivery ..............................45

Key Institutional Actors in the Response to Youth Vulnerability to HIV/AIDS ..................46

Chapter 6 Conclusion and Recommendations...............................................................50

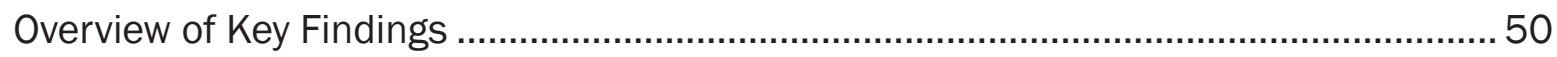

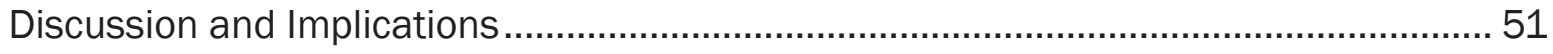

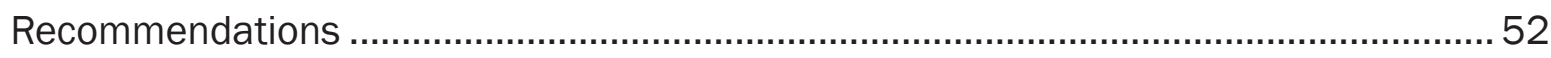

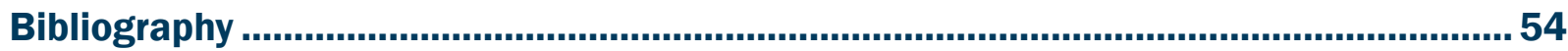




\section{LIST OF TABLES}

Table 1 Population-based estimates of HIV prevalence (\%) among individuals aged 15-49, by sex, age, and country

Table 2 Categories of youth targeted for the IDIs and FGDs in each focal country

Table 3 Number of interviews conducted per country.

Table 4 Summary of national strategic plans, based on data from qualitative inquiries

Table 5 Percentage of respondents aged 15-24 that had sex on or before age 15, by country and sex

Table 6 Percentage of never-married respondents aged 15-24 that are currently sexually active by country, and sex

Table 7 Percentage of respondents aged 15-24 who used a condom at last sex among those with multiple partners in the past 12 months by country and sex

Table 8 Relative risk ratios from logistic regression analysis of predictors of sexual debut on or before age 15 by country.

Table 9 Relative risk ratios from logistic regression analysis of predictors of current sexual activity among never-married youth aged $15-24$ by country

Table 10 Relative risk ratios from logistic regression analysis of predictors of condom use during last sex among sexually active youth who had multiple partners in the past 12 months by country

Table 11 Relative risk ratios from logistic regression analysis of predictors of comprehensive knowledge of HIV among respondents by country

Table 12 Summary of key institutional stakeholders

Table 13 Proportion of HIV-funding allocation in the six focal countries

\section{LIST OF FIGURES}

Figure 1 Among respondents who were sexually active in the past 12 months, percentage reporting having multiple sexual partners, by age, sex, and country

Figure 2 Among respondents with multiple sexual partners in the past 12 months, percentage reporting condom use at last sex, by age, sex, and country.....

Figure 3 Percentage of respondents reporting ever being tested for HIV and having received the results, by age, sex, and country

Figure 4 Percentage of respondents reporting correct answers on all five indicators of HIV knowledge, by age, sex, and country 


\section{Foreword}

This report is based on a multi-country study of African youth's HIV/AIDS vulnerabilities and stigma commissioned by Ford Foundation in 2011. It was informed by the realization that despite being disproportionately infected and affected by HIV/AIDS, accurate and timely evidence was lacking on the multiplicity of factors and impacts associated with the HIV prevention and impact mitigation needs of different categories of 10-24 year-olds in Africa.

The study undertook a fairly comprehensive examination of the HIV prevention and impact mitigation issues facing young people in Nigeria, Senegal, Egypt, South Africa, Uganda, and Kenya. It also reviewed the associated legal, policy and programmatic responses. In so doing it helps to bring into sharper relief, the critical need for more informed attention to the diversity of young people as beneficiaries and agents of change within HIV interventions on the continent. Accordingly, the range of issues covered and multidisciplinary perspectives addressed in the report open up new and refreshed prospects for more nuanced analysis and policy engagement and practice with youth dimensions of the HIV epidemic.

The report uncovers notable gaps in ongoing HIV prevention programs for young people on the continent. Despite the significant differences in HIV prevalence, socio-cultural milieu and legal context between the six focal countries youth remain a vulnerable group in all countries. Adolescent female sex workers, young men who have sex with men, street youth, rural and urban poor youth and youth who inject drugs are shown to be particularly vulnerable to HIV infection and lack of access to youth-friendly health and related social services. A corollary to this situation is the disturbingly limited engagement of youth in HIV policy making and implementation. There appears to be a persisting mismatch between what is developed for youth and what they expect from policy makers, program managers, and services providers.

The report's comparative analysis provides insights and evidence for better planning, designing, allocating resources to, and evaluating policies and programs that address the HIV vulnerabilities of the various categories of youth across Africa. The report recommends a number of key strategic actions for making the HIV response more relevant and effective for young people including the types of communication, advocacy and economic empowerment interventions and operations research that are critically needed.

It is our hope that this report will help stimulate the much needed boost for a more focused, well-resourced and sustained research and policy engagement with HIV youth vulnerabilities and responses across Africa. There is no doubt that such efforts would help to fast-track Africa's progress towards the global goals of zero new HIV infections, zero HIV-associated discrimination and zero AIDS-related deaths.

Adhiambo Odaga

Ford Foundation

Representative for West Africa \Director Pan Africa Programs

\section{FORDFOUNDATION}

Working with Visionaries on the Frontlines of Social Change Worldwide 


\title{
Abbreviations/Acronyms
}

\author{
AIDS Acquired immune deficiency syndrome \\ ART Antiretroviral treatment \\ ARV Antiretroviral \\ CEDAW Convention on the Elimination of All Forms of Discrimination against Women \\ Council Population Council \\ FGD Focus group discussion \\ FSW Female sex worker \\ GTZ German Technical Cooperation \\ HCT HIV counseling and testing \\ HIV/AIDS Human immunodeficiency virus/acquired immune deficiency syndrome \\ IDI In-depth interview \\ IDU Injecting drug user \\ IEC Information, education, and communication \\ KII Key informant interview \\ LGBTI Lesbian, gay, bisexual, transgender, intersex \\ MARP Most at-risk population \\ MSM Men who have sex with men \\ NGO Nongovernmental organization \\ OVC Orphans and vulnerable children \\ PLHA People (person) living with HIV/AIDS \\ PMTCT Prevention of mother-to-child transmission \\ PPJ Youth Promotion Project (Projet Promotion des Jeunes) \\ SRH Sexual and reproductive health \\ STI Sexually transmitted infection \\ UNGASS United Nations General Assembly Special Session \\ VCT Voluntary counseling and testing
}




\section{Executive Summary}

This study, implemented between August 2011 and July 2012, sought to provide a comprehensive, evidencebased picture of the HIV-related issues facing young people across Africa, and the prevailing legal, policy, and programmatic responses. The study was designed to establish a basis for a sharper focus on youth within the response to HIV on the continent.

Our researchers conducted country-specific analytical reviews of the relevant literature on factors associated with HIV risk-taking and health-seeking behaviors among young people aged 15-24 in six countries across Africa-Egypt, Kenya, Nigeria, Senegal, South Africa, and Uganda. In addition, qualitative and quantitative analyses enabled an evaluation of the similarities and differences among countries regarding factors associated with young people's sexual risk behavior, HIV-related health-seeking behavior, and the extent of policy and programmatic involvement.

Between February and July 2012, the Population Council, in collaboration with leading sexual and reproductive health (SRH)/HIV-focused youth-serving nongovernmental organizations (NGOs) from the six focal countries, conducted the following qualitative inquiries:

- Focus group discussions (FGDs), each made up of 6-12 participants.

- In-depth interviews (IDIs) with individuals perinatally infected with HIV; sex workers; orphans; married adolescents; and lesbian, gay, bisexual, and transgender (LGBTI) individuals. The participants represented an age- and gender-balanced population.

- Key informant interviews (KIIs) with stakeholders in the arena of policies and programs regarding SRH/HIVrelated issues facing youth.

The quantitative analysis consisted of secondary analyses of national HIV/SRH-related survey datasets, including Demographic and Health Surveys (DHSs), Integrated Biological and Behavioral Surveillance Surveys (IBBSSs), and other national datasets from the six study countries. Multivariate analyses using logistic regression were conducted on individual country datasets, with all regressions weighted to generate relative risk ratios with cluster-robust standard errors.

\section{MAIN FINDINGS}

\section{Legal and Policy Issues in Youth Vulnerabilities to HIV and Sexual Health Problems}

\section{Responsiveness of national laws and policies}

Identifiable components that exacerbate young people's vulnerabilities to HIV/AIDS include:

- Inconsistent definitions of youth/children;

- Nondomestication of key international and regional protocols;

- Inadequate enforcement of existing protective provisions or policies;

- Presence of punitive and repressive laws affecting stigmatized and vulnerable groups;

- Silence, denial, or neglect of particular sensitive issues.

Where protective laws do exist, there is often a lack of enforcement or the existence of legal pluralism in which multiple and contradictory legal regimes (i.e., civil, customary, Islamic) coexist. Such challenges are especially visible in the age at marriage/forced marriage for girls, age of consent, and access to services. 
In Egypt, for example, the agreement signed by the father of the bride and groom in Urfi or Sunna marriages has been used to bypass the legal age of marriage. Government officials are often aware of those unregistered marriages, but no legal action is taken against the girl's or groom's parents. Nigeria has the added complication of being a federal republic where each state has the autonomy to draft its own individualized legislation, leading to the presence of contradictory laws that negatively impact the vulnerabilities of young people. In South Africa, despite the legislature's increased efforts to create a platform in which health-care providers can initiate more open discussion with youth regarding SRH, contradictory laws continue to undermine the alleviating effects of these efforts especially in more rural and traditional settings.

Across all countries, most survey respondents thought that existing laws and policies did not promote the well-being of young people involved in sex work, injecting drug use, same-sex practices, and street families. Aside from Senegal, criminalization of sex work was the norm in the study countries. In Kenya, Nigeria, and South Africa, men who have sex with men (MSM) are mentioned as a vulnerable group within national HIV/AIDS policies. In Egypt and Uganda, no mention is made of MSM, although evidence shows a higher prevalence of HIV infection in this subpopulation than the general population. In Egypt, for example, the estimated prevalence among MSM is 6 percent, compared with less than 0.1 percent in the general population. ${ }^{1}$

\section{Youth Focus in Policies and Program Strategies}

Across all countries, national AIDS and related policies make very few references to youth-specific and youthcentered provisions. Each of the study countries has developed a national HIV strategic plan that forms a basis for the HIV response. Overall, the strategic plans target youth as part of the general population. Only Kenya and Senegal appear to pay special attention to youth-specific issues. In Senegal, for instance, national guidelines in the fight against AIDS among youth have been developed for providers and stakeholders involved in the HIV response. The main concern expressed by stakeholders in Egypt, Kenya, Nigeria, and Uganda was poor implementation of existing youth-specific service-delivery guidelines due to unavailability of funds. Another factor contributing to poor youth involvement in policies and programs was the lack of awareness of, and/or poor training on, the use of existing guidelines by service providers and program managers.

\section{Legally Based Manifestations of HIV-related Stigma and Discrimination}

Progressive laws and policies regarding HIV-related stigma and discrimination are present across study countries, excluding Egypt, yet issues of poor enforcement are pervasive in all six countries. In South Africa, the Equality Court, the Labour Relations Act, and the Employment Equity Act all serve to protect people living with HIV/AIDS (PLHA) from various forms of HIV-related stigma and discrimination. Yet challenges remain with implementation because of the limited state capacity to enforce and educate people about the prevailing policies and legislation. Uganda's current HIV/AIDS policy mentions stigma and discrimination facing PLHA as an issue that must be addressed as part of HIV prevention strategies, but does not provide concrete steps for doing so. Senegalese laws on HIV and AIDS provide the right to nondiscrimination and the right to care and treatment, and also prohibit forcible testing and screening. Kenya's HIV and AIDS Prevention and Control Act includes antidiscriminatory provisions such as sections that outlaw discrimination in various aspects of life, but there have been few legal precedents on its application. In Nigeria, the lack of political will or motivation to pass a national law that will protect PLHA is evidenced by the fact that the Anti-Stigma and Discrimination Bill has remained stagnant in the National Assembly for the past five years, although a few states have passed similarly protective legislation. People living with HIV face severe legally based stigma and discrimination in Egypt, where certain population groups including drug users treated in rehabilitation units;

${ }^{1}$ Abud-Raddad, L. et al. 2010. Characterizing the HIV/AIDS Epidemic in the Middle East and North Africa: Time for Strategic Action. Washington, DC: World Bank. 
prisoners; foreigners who plan to work, study, or train in Egypt; and men or women seeking employment in the Gulf states, among others, are required by law to take an HIV test.

\section{Sexual Risk Behaviors}

This study identified risky sexual behaviors in both male and female youth. In all six countries, the proportion of males aged 15-24 who engaged in risky sex was much higher than that of females. Among never-married males aged 15-24 years, current sexual activity was higher in urban than rural areas, except in Uganda (urban-7.9 percent, rura-10.1 percent) and this was also true among females.

Self-reporting of multiple sexual partnerships was also higher among males (15-30 percent) than females (2-5 percent) across countries, suggesting that behavioral interventions among youth would be incomplete without addressing this multiple partnership component and highlighting the need for all youth to have access to SRH services and comprehensive sexuality education. More young men than young women acknowledged using a condom during high risk sex in the past year. The high rate of condom use in South Africa, which may be a result of vigorous prevention efforts, including condom messaging and distribution aimed at young people, should be highlighted. Levels of condom use at last sex among youths with multiple partners varied from 10 percent among females aged 15-19 in Uganda to 80 percent among South African males from the same age group. Barriers to using condoms included lack of knowledge about how to use them, cost, availability (especially in rural areas), fears about and distrust of condom effectiveness, and the perception that condoms themselves are a source of HIV. The low level of condom use among African youth is particularly worrisome because of the high levels of high risk sexual activity. Increased condom messaging and distribution and the inclusion of condom/sexual negotiation skills in HIV prevention programs are essential.

Less than 60 percent of youth had comprehensive knowledge of HIV/AIDS, as constructed through a composite of the five United Nations General Assembly Special Session (UNGASS) indicators for HIV knowledge, and more urban than rural youth had comprehensive knowledge of HIV. Moreover, uptake of HIV testing remained low among youth in all countries (ranging from 1-43 percent) except in Kenya, where 69 percent of females aged 20-24 reported having had an HIV test and received the result.

\section{Factors Associated with Sexual Risk and Health-seeking Behaviors among Youth}

\section{Risky sexual behaviors}

Variables significantly associated with risky sexual behaviors in the country-specific logistic regression analysis included being male (compared with being female), and being currently employed (compared with Not working). In addition, compared with never-married youth who had no education, those with tertiary education were significantly more likely to engage in current sexual activity than were those without education, as were those with secondary or primary education. Early sexual debut was, on the other hand, most strongly predicted by being ever-married.

\section{Condom use during last sex among youth in multiple sexual partnerships}

Compared to males, females were less likely to use condoms during risky sexual activities. Also, though higher educational status was associated with greater likelihood of engaging in multiple sexual partnerships, it was also associated with greater use of condoms during such high risk sex, compared with those without education. 


\section{Comprehensive Knowledge of HIV}

Compared with youth aged 15-19 years, those aged 20-24 years were slightly more likely to have comprehensive knowledge of HIV. Education (tertiary; RRR: 6.77; secondary; RRR: 4.43; primary; RRR: 2.55; compared with no education) and wealth (fourth quintile; RRR: 1.76; third quintile; RRR: 1.46; second quintile; RRR: 1.31 compared with first quintile) were significantly associated with comprehensive knowledge. These findings are plausible because being in the upper socioeconomic class almost certainly guarantees better education, which impacts knowledge.

\section{HIV Youth-focused Responses at the Individual, Institutional, and Policy Levels}

\section{Individual level}

At the individual level, the qualitative inquiries showed that most young people considered SRH to be a significant need among youth. Respondents felt strongly about the link between the risk of acquiring HIV and risky sexual behavior, poor communication skills, and sexual violence. Despite their consideration of SRH as a priority, youth overwhelmingly felt powerless to adequately respond to their HIV and SRH vulnerabilities because of inadequate knowledge, issues with service providers and set-up of services, and livelihood struggles. Respondents often mentioned service-provider issues such as stigmatizing attitudes and a lack of confidentiality and competence as deterrents to young people's seeking HIV and SRH services, especially in public health facilities. Limited real involvement exists in the planning, delivery (beyond peer information, education, and communication [IEC]), and management of programs and services.

\section{Institutional and policy levels}

Across all countries, institutional responses at the community and national levels continue to fall short of the needs and expectations of young people in the areas of HIV and SRH education and access to youth-friendly services, especially for the most vulnerable groups. The failures of institutional responses in the study countries can be tied to the broader issue of denial and lack of openness about youth sexuality. Participants stated that sex education in primary and secondary schools only covers a narrow set of topics, mostly limited to abstinence. Condom use, family planning, and HIV counseling and testing (HCT) appear not to be taught, yet study participants viewed them as important in taking preventative action. For out-of-school youth, HIV and SRH information is obtained through community channels such as community outreach activities, peer education, and seminars which may only reach a very small proportion of such youth.

For well-established epidemics (as in Kenya, South Africa, and Uganda), the growing population of perinatally infected adolescents, though long-acknowledged, has attracted little or no systematic programmatic responses to its SRH needs and concerns. Interviews with key stakeholders and program managers reveal that few high-quality SRH and HIV policies exist for youth, but inadequate resourcing (funding, infrastructure, personnel, and supplies) of programs and services, especially for rural and poor urban youth, out-of-school youth, and young most at-risk populations, severely limits their overall impact.

\section{RECOMMENDATIONS}

- Improving sexual health-seeking behaviors, especially uptake of HCT by male youth, and condom use by female youth, through a combination of youth-accessible communication channels, is imperative.

- Evidence-based advocacy needs to be targeted at policymakers and donors to bring greater attention to the youth dimensions of the HIV epidemic, especially in relation to neglected vulnerable youth. 
- Innovative operational research is called for to better understand how to increase the meaningful involvement of young people in the conception, planning, and implementation of SRH and HIV/AIDS policies and programs.

- Efforts to promote the mainstreaming of youth-friendly SRH and HIV services are required given the challenges of scaling up and sustaining the few model stand-alone services provided largely by nongovernmental organizations (NGOs).

- A strong case exists for systematic domestication of key international regional protocols to align to individual country contexts.

- Alignment of national and subnational laws and of civil, customary, and religious laws need to be advocated for strongly to ensure that laws and policies are not contradictory, and implementation of existing youth-specific laws and policies need to be improved.

- National AIDS coordinating agencies must live up to their oversight function of ensuring that young people are not neglected in national HIV policies and programs.

- Governments need to increase funding and demonstrate ownership and sustainability of youth-based HIV programs. 


\section{Chapter 1 Background}

Africa's young people aged 15-24 are disproportionately infected and affected by HIV/AIDS. Nearly 4 million ${ }^{2}$ sub-Saharan African youth currently live with the virus, and 20 countries in sub-Saharan Africa accounted for about 69 percent $^{3}$ of all new HIV infections globally among young people in 2009 . HIV prevalence is more than twice as high among young girls (3.4 percent) than among their male counterparts (1.4 percent). ${ }^{4}$ Across the continent, HIV prevalence among young people varies considerably from less than 0.1 percent in Egypt (with its highly concentrated epidemic among injecting drug users [IDUs] and MSM) ${ }^{5}$ to more than 25 percent in Zimbabwe. Nigeria and South Africa have the highest number of adolescents living with HIV/AIDS: as many as 1.3 million in Nigeria and 1.9 million in South Africa. ${ }^{6}$ African youth have suffered disproportionately from the effects of the epidemic. Millions have lost at least one parent to AIDS, eight out of ten individuals orphaned by AIDS live in Africa, and an estimated 55 percent of all AIDS orphans in the region are adolescents. ${ }^{7}$

These broad statistics, however, mask huge variations in HIV prevalence and its impact among different subgroups of young Africans, who represent a highly heterogeneous population. Factors that may affect HIV exposure and impact include gender, marital status, level of education, employment status, rural-urban residence, migration status, sexual activity, living arrangements (with one, two, or no parents), HIV status, age, nationality, legal contexts, religion, and household economic status. ${ }^{8}$

The impact of the epidemic on young people, especially among females aged 20-24 years (see Table 1), calls for close attention to the youth dimensions of the epidemic. Adolescents and young adults constitute about one-third of the total population of Africa, ${ }^{9}$ and their well-being is intricately tied to the continent's prospects for sustainable development. Without accurate and timely evidence, policymakers and program planners/ managers will not be able to properly plan, design, or allocate resources to monitor and evaluate policies and programs that effectively address the HIV prevention and impact-mitigation needs (including stigma and discrimination) of the various categories of youth across Africa. Generating such evidence would positively affect the course of the epidemic in Africa, the epicenter of the global pandemic, since trends and patterns in HIV prevalence among young people tend to significantly shape overall trends in new infections.

A recent study commissioned by UNAIDS ${ }^{10}$ showed that although young people across Africa still account for about 40 percent of new infections, they also tend to lead the process of wider adoption of safer-sex behaviors in countries that have experienced recent, significant declines in HIV prevalence, including Kenya and South Africa.

\footnotetext{
2UNICEF. 2011. "Opportunity in crisis: Preventing HIV from early adolescence to young adulthood." New York: UNICEF. 3UNAIDS. 2011. AIDS at 30: Nations at the Crossroads. Geneva: UNAIDS

"UNAIDS. 2009. “2009 report on the global AIDS epidemic." Geneva: UNAIDS

${ }^{5}$ Parker, W. et al. 2007. "Concurrent sexual partnerships amongst young adults in South Africa: Challenges for HIV prevention communication." Johannesburg: CADRE.

"UNAIDS. 2009. "2009 report on the global AIDS epidemic." Geneva: UNAIDS

${ }^{7}$ Biddlecom et al. 2007. "Protecting the next generation in sub-Saharan Africa: Learning from adolescents to prevent HIV and unintended pregnancy." New York: AGI.

8World Bank. 2008. "The World Bank's commitment to HIV/AIDS in Africa." Washington, DC: World Bank.

${ }^{9}$ Population Council and UNFPA. 2003. "Adolescent and youth sexual and reproductive health: Charting directions for a second generation of programming." New York: Population Council; Biddlecom et al. 2007, op. cit.; Santis et al. 2007. "Involving young people in efforts to combat HIV and AIDS in Africa." Washington, DC: EDC.

${ }^{10}$ UNAIDS. 2010. "Trends in HIV prevalence and sexual behaviour among young people aged $15-24$ years in countries most affected by HIV.” Geneva: UNAIDS.
} 
TABLE 1 Population-based estimates of HIV prevalence (\%) among individuals aged $15-49$, by sex, age, and country

\begin{tabular}{|c|c|c|c|c|c|c|}
\hline \multirow{2}{*}{$\begin{array}{l}\text { Country/ } \\
\text { Survey Year }\end{array}$} & \multicolumn{3}{|c|}{ Male } & \multicolumn{3}{|c|}{ Female } \\
\hline & $15-19$ & $20-24$ & $15-49$ & $15-19$ & $20-24$ & $15-49$ \\
\hline Egypt (2005) & na & na & 0.02 & na & na & 0.02 \\
\hline Kenya $(2007)^{b}$ & 1.0 & 1.9 & 5.8 & 3.5 & 7.4 & 9.2 \\
\hline Nigeria $(2007)^{c}$ & 2.1 & 1.9 & 3.2 & 1.3 & 4.5 & 5.0 \\
\hline Senegal $(2005)^{d}$ & 0.0 & 0.2 & 0.4 & 0.2 & 0.8 & 0.9 \\
\hline South Africa $(2008)^{e}$ & 2.5 & 5.1 & * & 6.7 & 21.1 & * \\
\hline Uganda $(2004 / 5)^{f}$ & 0.3 & 2.4 & 5.9 & 2.6 & 6.3 & 7.9 \\
\hline
\end{tabular}

Sources: a'World Bank 2005; ' $\mathrm{MOH}$ 2008, KAIS 2007; 'FMOH 2008, NARHS 2007; dNdiaye and Ayad 2006; 'HSRC 2009; National HIV Survey 2008; ${ }^{\mathrm{H}} \mathrm{MOH}$ and ORC Macro 2006, UHSBS 2004/5.

*Survey was limited to 10-24-year-olds. na $=$ Not available.
Nonetheless, the available evidence strongly suggests that young Africans, especially females, are highly susceptible to HIV/STIs and other SRH morbidities resulting from the high prevalence of high-risk sexual exposures and poor health-seeking behavior. In addition, African youth experience early sexual initiation, marriage, and first births. This population is also significantly sexually active but has limited knowledge

of HIV/STIs, reproductive health in general, and access to youth-friendly SRH services. Youth engage in highrisk behaviors such as multiple partnering and transactional sex in a context of relatively low-level condom and contraceptive use. Structural issues such as poverty, gender inequality, and high levels of stigma and discrimination contribute to and exacerbate these vulnerabilities.

A cursory review of regional and national HIV policies, programs, and strategic plans suggests that policymakers, planners, and program managers do not consider a strong focus on youth to be critical for HIV prevention and impact mitigation. This lack of attention is especially apparent when considering specific interventions, targets, outcome-level indicators, and resource allocations, as opposed to broad, strategic objectives geared toward universal access to comprehensive HIV prevention, care, and support services. Existing youth-focused programs are not widely available and also do not target hyper-vulnerable subpopulations such as sex workers, drug users, sexual minorities, and street youth. Although there are national policy frameworks that aim to combat youth HIV/SRH vulnerabilities, they are currently inadequate because of a failure to consider the diversity of youth and to therefore target hyper-vulnerable subpopulations.

Youth have been the least positively impacted by the recent increase in HIV funding to Africa despite bearing a disproportion of the burden of the epidemic. A large proportion of financial resources for HIV programs in several African countries from the three main international funding streams (the Global Fund, the World Bank's Multi-Country Program, and the United States President's Emergency Plan for AIDS Relief) in the past ten years have gone to HIV treatment rather than HIV behavior-change interventions, which are more relevant to young people. ${ }^{11}$ Indeed, national strategic plans often refer to young people only in the context of HIV prevention, yet prevention has been underfunded. African legal environments are often contradictory, with laws that both alleviate and exacerbate youth susceptibility, including laws that perpetuate gender inequality and further marginalize sexual minorities.

Evidence-based alignment of policies and programs is needed at the regional and national levels to address the fundamentally "youthful" character of the HIV epidemic and its inherent diversities. However, there is a dearth of robust youth-related data that are sufficiently disaggregated to shed enough light on specific vulnerabilities, including stigma and discrimination that young people face, especially for the most vulnerable subpopulations such as MSM and LGBTI, female sex workers, married adolescents, orphans, IDUs, prisoners, migrants, youth displaced by conflict, and youth born or living with HIV. It will be particularly useful to provide

${ }^{11}$ Oomman et al. 2007. Following the Funding for HIV/AIDS: A Comparative Analysis of the Funding Practices of PEPFAR, the Global Fund and World Bank MAP in Mozambique, Uganda and Zambia. Washington, DC: CGD. 
quantitative and qualitative data for a diversity of countries to highlight underlying commonalities and crucial differences in the HIV vulnerabilities of youth across Africa, to strengthen the evidence base for a focus on youth in any Pan-African HIV response or initiative. 


\section{Chapter 2 \\ Methods and Data Sources}

\section{GOAL AND OBJECTIVES}

The goal of this study is to provide a comprehensive, evidence-based picture of the HIV-related issues facing young people in Egypt, Kenya, Nigeria, Senegal, South Africa, and Uganda, and the prevailing legal, policy, and programmatic responses, to establish a basis for a sharper focus on youth within the response to HIV on the continent.

\section{Objectives:}

- Assess the extent to which relevant national policies, program strategies, and regional protocols are responsive to the HIV vulnerabilities of young people;

- Critically highlight the degree to which national HIV and SRH-related laws discriminate against young people and thwart their ability to access HIV and other sexual-health information and services and legal protection when violations occur;

- Examine empirically the commonalities and contrasts within the vulnerabilities of youth to HIV and AIDS in the six countries with regard to:

- SRH and HIV risk, related health-seeking behaviors, and their social, cultural, economic, and legal determinants; and

- the forms and nature of HIV stigma and discrimination that youth face and the consequences for their access to health and other services;

- Document the extent to which the needs, concerns, and perspectives of youth are addressed in ongoing national HIV programs, and whether youth are meaningfully engaged in the planning, implementation, and evaluation of HIV programs; and

- Identify key institutional stakeholders, at regional, subregional, and national levels, actively engaged in HIV/SRH-related policies and programs for young people.

\section{DEFINITIONS OF KEY TERMS}

Access to HIV Services: Tested for HIV in the past 12 months and received the results.

Age at Sexual Debut: The age at first sexual intercourse.

Comprehensive Knowledge of HIV: Knowing that consistent use of condoms during sexual intercourse and having just one HIV-negative, faithful partner can reduce the chances of HIV infection, knowing that a healthy-looking person can have HIV, and rejecting the two most common local misconceptions about HIV transmission and prevention.

Condom Use During Last Sex: Use of a condom during the last sexual intercourse.

Discrimination: Obtained by proxy through respondents' admission of the following: (a) knowing someone who has been denied services because of HIV, (b) knowing someone who has been denied involvement in social events because of HIV. 
Multiple Sexual Partners: Having sexual intercourse with more than one sexual partner in the past 12 months.

Sexually Active: Had sexual intercourse within the last 30 days.

Risky Sexual Behaviors: We considered the standard definition of 'high-risk sex' used in all the surveys as inadequate for rigorous analysis as it basically regards all forms of sexual intercourse by unmarried sexually active youth (except with a partner they are living with) as 'high risk'. We therefore approached risky sexual behavior through three more robust proxy indicators (based on adequacy of numbers across cells of generated tables) than the adopted survey definition of high risk sex as sex with a nonmarital, non-cohabiting partner over the past 12 months. These three proxies are sexual debut before age 15, current sexual activity among unmarried youth, and engagement in multiple sexual partnerships in the last 12 months among sexually active youth.

Stigma: Obtained by proxy through expression of the following attitudes: (a) wanting to keep secret that a family member has HIV, (b) unwillingness to care for someone with AIDS, (c) unwillingness to buy fresh vegetables from a shopkeeper who has HIV, (d) saying that a teacher with HIV who is not sick should not be allowed to continue teaching.

Youth: The concept of youth varies across cultures and societies and the definition changes in response to the context, shifting to accommodate fluctuating political, economic, and sociocultural realities. The age range of 15-24 is often used by the United Nations and other international organizations for the ease of statistical comparison. In the context of HIV prevention and an exploration of the vulnerabilities of youth, young people aged 10-14 are pivotal because life skills, specifically safer-sex practices, acquired during this age range can positively influence the transition from adolescence to adulthood..$^{12}$ This age group is also thought to be particularly vulnerable to sexual coercion. However, this study only focused on youth ages 15-24 because of the minimal data available on vulnerabilities among 10-14-year-olds. The terms "youth," "young people," and "adolescents" are used interchangeably in this report and all refer to the age group $15-24$.

Study Sites: This study was conducted in six countries across Africa-Egypt in the North, Nigeria and Senegal in the West, Kenya and Uganda in the East, and South Africa in the South.

\section{STUDY METHODS}

\section{Literature Review}

The Council conducted country-specific analytical reviews of relevant literature by using a standardized organizing frame focusing on factors associated with HIV risk-taking and health-seeking behaviors among adolescents across Africa. The empirical evidence on HIV-related stigma and discrimination among and toward young people, which is usually measured compositely through responses to questions on attitudes and intentions toward people living with HIV and AIDS, was also reviewed.

\section{Legal and Policy Assessment}

Gender equity and rights-based content analyses and reviews of relevant national laws, policies, and program strategy documents were conducted in each country to ascertain:

${ }^{12}$ Sedlock. 2000. "Reaching the youngest adolescents with reproductive health programs," In FOCUS Series. Washington DC: Focus on Young Adults. 
a. The extent to which these laws and policies recognize, respond to, and address the HIV prevention and impact-mitigation needs and perspectives of young people in all their diversities (age, marital status, HIV status, employment status, sexual orientation, etc.); and

b. Whether the laws and policies elevate or reduce the exposure of young people to HIV infection and SRH problems and related stigma and discrimination by the way they treat issues such as:

- age of consent (for sex, marriage, and SRH/HIV services)

- sexual abuse (rape, incest, etc.)

- violence against women

- LGBTI rights

- access to safe abortion services

- legal status of sex work

- trafficking of girls and young women

- HIV-related stigma and discrimination

\section{Secondary Analyses of National Survey Datasets}

a. Demographic and Health Surveys (DHSs), Integrated Biological and Behavioral Surveillance Surveys (IBBSSs), and other HIV/SRH-related national survey datasets in the six study countries were analyzed to discern the risk behaviors, health-seeking behaviors, and HIV-related stigma and discrimination among young women and men aged 15-24. The datasets analyzed included: the DHS for Egypt 2008, Kenya 2009, Nigeria 2008, Senegal 2005, and Uganda 2008; the IBBSS for Kenya 2010 and Nigeria 2010; the National HIV/AIDS and Reproductive Health Survey for Nigeria 2007 (NARHS Plus); and the 2004 South Africa National HIV Prevalence, Behaviour, and Communication Survey.

Country-specific statistical analyses of the national HIV/SRH-focused behavioral survey datasets included: the key dependent variables-risky sexual behaviors (measured via sexual debut before age 15, current sexual activity among never-married youth, and multiple sexual partnerships among sexually active youth) age at sexual debut, condom use, uptake of HIV testing, and attitudes toward persons living with HIV; and the key social and economic characteristics-age, marital status, formal schooling status, residential milieu, household economic status, and employment status, among others to the extent allowed by the available data. Data was not collected on particular key dependent variables in all the focal countries except Uganda. The Egypt DHS did not collect data on any of the key dependent variables, while the Kenyan and Senegalese surveys did not collect data on respondent's knowledge of any person living with HIV that had been denied access to health services. The Nigerian NARHS, on the other hand, did not collect data on some behaviors related to high risk sex while the South African survey excluded some key questions related to HIV stigma and discrimination and comprehensive knowledge of HIV. The gaps in the Egypt DHS data were partially compensated for with data from the largely urban Population Councilimplemented 2009 National Survey of Young People in Egypt. Also, marital status, living arrangement, and religion were not included in the multivariate analysis because the sample sizes for married youth surveyed in all the datasets were relatively small and the distributions were highly skewed for these variables. Despite these gaps, the findings from the statistical analysis provided a quantitative description of the HIV vulnerabilities of youth across Africa. Comparative interpretation of the findings was used to ascertain commonalities and differences across the six focal countries.

As discussed previously, the work focused on youth aged 15-24 because of the dearth of data on vulnerabilities among 10-14-year-olds. The Council's review of the DHS in several African countries since 2004 showed that-despite offering a key source of comparable, nationally representative, populationbased estimates of HIV prevalence and HIV risk-bearing and health-seeking behaviors-none elicited data from young people aged 10-14. 
However, it was possible to use information from those aged 15 and older to document experiences from earlier ages. For example, reports of sexual debut occurring at age 14 or younger were used to infer sexual activity among younger teens not interviewed. Additionally, FGDs and IDIs were also used to elicit qualitative data from 15-17-year-old youth in all the study countries and included exploration of sexual activity before age 15 . Although these are not perfect tools, they do help advance our understanding of risks faced by those younger than 15 years of age.

b. Multivariate analyses using logistic regression were conducted on individual country datasets. All regressions were weighted to generate relative risk ratios with cluster-robust standard errors. The weights were normalized by survey sample size to give countries equal weights. Based on data availability, patterns highlighted by the preceding bivariate analysis, and theoretical significance implied by the relevant literature, the following variables were included as predictors in the regression models-age (1519 and 20-24), gender, rural-urban residence, level of educational attainment (none, primary, secondary, and tertiary), employment status, and wealth quintile (1-5) based on respondent's household ownership of consumer goods and characteristics of dwelling (electricity, radio/TV, motorbike/car, water supply, and house floor type). Only estimates for variables that turned out to be significant at $p<0.01$ and $p<0.05$ in the regression models are presented and discussed. Also, relative risk ratios are presented rather than odd ratios because they tend to be easier to interpret, for example, RRR of 3.0 means group is three times more likely than the reference category. We analyzed the country-specific regressions by identifying and discussing the similarities and differences between the focal countries to draw insights on commonalities and country specificities around the factors that drive youth vulnerabilities to HIV and AIDS and their sexual health-seeking behaviors.

\section{Qualitative Inquiries}

FGDs, IDIs, and KIls were conducted between February and July 2012 in Egypt, Kenya, Nigeria, Senegal, South Africa, and Uganda by the Population Council in collaboration with the foremost youth-serving SRH/ HIV-focused national NGOs in each of the six countries. Young people were recruited for FGDs to achieve diversity regarding age, gender, sexual orientation, schooling, and marital and HIV status. For each country, between five and seven FGDs (each made up of 6-12 participants) were conducted: three to five were conducted separately by sex for groups of youth aged 15-19 and 20-24, along with one male and one female group of young people aged 15-19 living with HIV. Potential FGD participants were identified in each country by two leading national youth-serving NGOs. The nominating NGOs were asked to contact potential participants identified systematically from their current program and service beneficiaries (segmented by age, gender, and HIV status) and ask whether they wanted to participate in the study. Trained interviewers administered informed consent with young people aged 18 years and older who agreed to participate, or with parents/guardians of youth aged 15-17.

IDIs were conducted in each country to document young people's experiences and the lessons they learned about accessing HIV and related SRH services, including preventing mother-to-child transmission (PMTCT). In each country, interviews were conducted with young people balanced by gender and age across five categories: persons perinatally infected with HIV, sex workers, LGBTI, orphans, and married adolescents. Credible youth-serving NGOs and HIV service providers assisted the country research team in identifying potential participants. Table 2 summarizes the distribution of the categories of youth targeted for the IDIs and FGDs per country.

The KIls targeted stakeholders with policy and/or programmatic experience regarding the salient SRH/ HIV-related issues facing youth. Stakeholders interviewed included program managers, peer educators, youth leaders, HIV service providers, and legal advocates. Representatives of key international and national organizations involved in the HIV response in the project countries were also interviewed, including funding agencies (USAID, the World Bank, Family Health International, and the Ford Foundation), relevant agencies of 
the United Nations (UNAIDS, UNFPA, and UNICEF), subnational and national AIDS policy-coordinating agencies, managers of major HIV service-delivery programs or projects (including one focused on human rights/legal protection), and SRH- and HIV-focused governmental and nongovernmental organizations serving youth. Respondents were selected based on consultations with the national AIDS control agencies, Ford Foundation program staff, and recommendations from experienced professionals and researchers in the SRH and HIV fields in each country, and were selected to achieve diversity regarding gender, sectoral/professional background, and geographic location.

\section{INSTRUMENT DEVELOPMENT AND ANALYSIS}

Standardized interview guides were developed in a collaborative, iterative process coordinated by the project team through a joint review by the Population Council country technical leads and Ford Foundation program staff. The FGD guide explored participants' experiences with accessing SRH and HIV prevention, treatment, care, and related educational and legal services, including issues regarding distance and location, provider attitudes, and cost of services. IDIs explored personal experiences with using services, quality of care (especially in relation to stigma and discrimination), and youth participation in program development and service delivery. The KIls explored the following major themes: allocation of resources toward the youth dimensions of the HIV response, policy and service delivery gaps, social and legal barriers to youth access to comprehensive HIV services, and recommendations regarding how to better target HIV/SRH programs and services to youth.

Trained researchers facilitated the group discussions in local languages: Arabic, English, or French. The interviews were tape-recorded, transcribed verbatim, translated into English, and analyzed using QSR Nvivo 9 Software.13 In total, 34 FGDs, 112 IDIs, and 84 KIls were conducted. Table 3 shows the breakdown of the interviews across the six countries of study.

TABLE 3 Number of interviews conducted per country

\begin{tabular}{lcccccc}
\hline Interviews & Egypt & Kenya & Nigeria & Senegal & South Africa & Uganda \\
\hline FGDs & 5 & 7 & 6 & 6 & 5 & 5 \\
IDIs & 10 & 21 & 29 & 31 & 5 & 16 \\
KIIs & 10 & 11 & 14 & 17 & 16 & 16 \\
\hline
\end{tabular}

$\overline{{ }^{13} \text { QSR Nvivo } 9 \text { Software (International Pty 2007, Australia) }}$
TABLE 2 Categories of youth targeted for the IDIs and FGDs in each focal country

\begin{tabular}{lcccc}
\hline Category & \multicolumn{2}{c}{ IDIs } & \multicolumn{2}{c}{ FGDs } \\
& Male & Female & Male & Female \\
\hline 13-14 & 2 & 2 & - & - \\
15-19 & - & $2^{\mathrm{b}}$ & 1 & 1 \\
15-19 living with HIV & 2 & 2 & 1 & 1 \\
20-24 & - & $2^{\mathrm{b}}$ & 1 & 1 \\
20-24 LGBT & 2 & 2 & - & - \\
Married adolescents & 2 & 2 & - & - \\
\hline Total $^{c}$ & $\mathbf{8}$ & $\mathbf{1 2}$ & $\mathbf{3}$ & 3 \\
\hline
\end{tabular}

Note: ane, an orphan and the other, living with both parents; 'Sex worker; 'The actual IDIs and FGDs successfully conducted as shown in Table 3 turned out to be higher or lower across the six countries due to fieldwork exigencies. 


\section{ETHICAL CONSIDERATIONS}

The study was approved by the Institutional Review Board of the Population Council and by the research ethics review committees in each of the focal countries except Egypt, where this was not a requirement. In Kenya, the study was reviewed by KEMRI/National Ethics and Review Committee, in Nigeria by the Institutional Review Board of the Nigerian Institute of Medical Research (IRB-NIMR), in Senegal by the National AIDS Research Ethics Committee, in South Africa by the National Health Research Ethics Review Board, and in Uganda by the Ethics and Review Committee of the Uganda National Council for Science and Technology.

Concerns about participants' confidentiality and safety made it preferable to conduct interviews at central venues. For similar reasons, participants were asked to provide pseudonyms during FGDs, which they were encouraged to use when referring to other participants. Only pseudonyms have been used in this report. Study participants taking part in FGDs and IDIs were given transport reimbursement in accordance with local practices and rates to cover transportation and time costs, and refreshments were provided.

\section{LIMITATIONS OF STUDY}

A few limitations are worth noting. First, although the selection of different groups of youth and stakeholders according to predefined criteria enabled the study to capture a range of experiences, the samples, particularly the qualitative samples, may not be representative of all young people and actors in the SRH and HIV contexts in the six countries of study. Second, the reported norms and experiences may be specific to particular local contexts, making difficult the identification and assessment of the similarities and differences between the six countries. Third, some national datasets lacked some or all dependent variables. In seeking to ascertain the factors associated with sexual-risk and health-seeking behaviors among young people across the six countries, this lack of information limited the depth of comparison possible between the countries. Fourth, the 2010 IBBSS dataset was not released by Egyptian authorities and the 2008 DHS did not elicit data on key sexual-risk and health-seeking behaviors, resulting in the exclusion of Egypt from most of the quantitative analysis. Nonetheless, the breadth, depth, and multiplicity of data sources and types give us appreciable confidence in the robustness of the findings and conclusions. 


\section{Chapter 3}

\section{Legal and Policy Issues in Youth Vulnerabilities to HIV and Sexual Health Problems}

\section{RESPONSIVENESS OF NATIONAL LAWS AND POLICIES: COMMONALITIES AND DIVERGENCES}

Although the legislative and policy milieus across all six countries include provisions that alleviate and are responsive to young people's vulnerabilities to HIV and SRH morbidity, they also have components that exacerbate these vulnerabilities. These failures occur along broad lines: inconsistent definitions of youth/child, non-adoption and adaptation at the country level of key international and regional protocols, inadequate enforcement of existing protective provisions or policies, presence of punitive and repressive laws affecting stigmatized and vulnerable groups, and silence, denial, or neglect of particular sensitive issues.

Despite being signatory to several key international and regional protocols (e.g., African Charter on Human and People's Rights, CEDAW, Maputo Protocol) that have the potential to reduce the HIV-related vulnerabilities of young Africans, most of the study countries have failed to adapt and adopt them locally or have laws that violate such treaties and protocols. For example, Nigeria is signatory to the Convention on the Rights of the Child, yet it has only partially domesticated its provisions with only a few states ratifying them.

Where protective laws do exist, they are often not enforced. Additionally, in some settings legal pluralism exists, wherein multiple and often contradictory legal regimes (i.e., civil, customary, and religious) coexist. Such circumstances are of particular consequence for age at marriage/forced marriage among girls, age of consent, and access to services. For example, in Egypt the legal age of marriage for men and women is 18 years, ${ }^{14}$ however for sociocultural reasons, some families, especially those in rural areas, choose to marry off their daughters before that age. To bypass the law, parents resort to Urfi or Sunna marriage, which involves an agreement signed by the fathers of the bride and groom. This contract is not registered in official documents until the girl turns 18 . In some cases, the girl's consent is not sought before such a marriage agreement is signed. There are other instances of intergenerational marriages where the groom is many years older and more sexually experienced than the bride, thus placing her at risk of sexually transmitted infections, including HIV/AIDS. In an attempt to prevent child marriage and trafficking of girls under the guise of marriage, a law has been passed requiring that the age difference between two partners be no more than 30 years, but some parents still circumvent that law by engaging in traditional marriages. Government officials are often aware of these unregistered marriages, but no legal action is taken against the girl's parents or the groom.

\footnotetext{
$\overline{{ }^{14} \text { See "Review of laws }}$ and policies pertaining to youth sexual and reproductive health with special emphasis on HIV/AIDS-Egypt" commissioned by the Population Council, June 2012.
} 
Similarly, in Uganda, marriage is regulated by various laws, and this legal pluralism creates confusion with regard to the rights and obligations of parties in a marriage. ${ }^{15}$ Marriages entered into under the Marriage Act (that is, before a Registrar or in a Church) are strictly monogamous, but customary law permits polygamy, thus legalizing multiple sexual partnerships and increasing the risk of HIV infection, especially for women. Although there is a case to be made that polygamy violates Article 33 of the Constitution of Uganda, which provides that "laws, cultures, customs, or traditions which are against the dignity, welfare, or interest of women, or which undermine their status, are prohibited by this Constitution," the contradiction still remains.

In Nigeria, which is a federal republic, legal pluralism has an added complication. Each state has autonomy to draft its own individualized legislation, resulting in contradictory laws that negatively impact the vulnerabilities of young people. ${ }^{16}$ In South Africa, the legislature has been progressive in creating a platform for health-care providers to initiate discussion with respect to SRH more openly with youth. ${ }^{17}$ Nevertheless, contradictory laws that reverse the alleviating effects of South Africa's progressive laws continue to exist. For example, the age of consent for access to services such as abortion, contraception, and HIV counseling and testing (HCT) is 13, but the Sexual Offences Act creates a potential barrier to accessing SRH services by establishing sex before the age of 16 as a criminal offense, even when it is consensual.

Across all six countries, laws exist that are considered repressive and punitive to most at-risk populations (MARPs), and particularly to sex workers, drug users, and MSM. Young people interviewed during the qualitative inquiries generally acknowledged that some of their country's laws and policies were repressive and undermined the rights of young people. For example, many participants stated that groups of youth who engaged in illegal or stigmatized activities were disproportionately affected by some of these laws. Most respondents believe that existing laws and policies do not promote the well-being of young people involved in sex work, injecting drug use, same-sex practices, and life on the street.

Criminalization of sex work is the norm in all study countries except Senegal. Criminalizing sex work exacerbates the HIV risks faced by sex workers because it decreases their negotiating power with clients, many of whom place a premium on unprotected sex. ${ }^{18}$ Criminalization also stops them from accessing medical services adequately because they fear discrimination and stigma. Young people who engage in sex work were considered by participants in the qualitative inquiries to be at increased risk of harassment by law enforcement agents, and indeed to be constantly mistreated in this way. Several respondents cited instances of police harassment, arbitrary arrests, and extortion for money or sexual services. The following quotes from FGD participants in Kenya and Uganda illustrate this point:

There is no protection of sex workers, considering the way that they are normally arrested by the city council askaris (officers).... They are thrown on top of the lorries by these askaris and, in fact, they are the same ones who abuse them.... Yes, those city council askaris say, 'Give it to us (sex) for free so that we can release you.'

FGD, Kenya, female 20-24

You see a police car on the side watching....and you find the police car doesn't have one policeman.... They then arrest those ladies. When they are taking them, they don't take them to the CPS or Jinja Road, they take them to the corner, let's say Centenary Park. They are like, 'Sleep with me, I let you go.' Because this lady fears the police...she sleeps with them.

FGD, Uganda, female positive 15-19 years

\footnotetext{
${ }^{15}$ See "The impact of HIV/AIDS on young people in Uganda: A critical analysis of legal, policy and programmatic responses" commissioned by the Population Council, March 2012

${ }^{16}$ See report on "The impact of legal and policy responses on the HIV/AIDS and SRH vulnerabilities of Nigerian youth" commissioned by the Population Council, February 2012.

${ }^{17}$ See "Legislative and policy review: Youth and HIV in South Africa" commissioned by the Population Council, February 2012.

${ }^{18}$ UNAIDS. 2002. “Sex work and HIV/AIDS: Technical update.” Geneva: UNAIDS.
} 
Criminalization of same-sex practice is also a commonality across all the countries except South Africa. Criminalization exacerbates homophobia and places sexual minorities, especially MSM, at greater risk of violent attack and HIV infection, because they are forced to conduct their relationships clandestinely and are less free to seek medical treatment and SRH services. ${ }^{19}$ The qualitative inquiries revealed that young people who are gay, lesbian, transsexual, or transgender are considered to be unprotected by existing provisions in the law in Egypt, Kenya, Nigeria, and Uganda. Moreover, they face widespread stigma and discrimination. For example, as explained by respondents from Uganda:

The government has not done anything. They actually discriminate against us, which is unfair yet we are all supposed to be treated equally like Ugandans. Up to now the police still torment us. I have been arrested a few times myself and charged with, ah, should I call it impersonation that I have been masquerading around as a woman, which is really not true because that's my nature. Because I have long hair they have arrested me, yet some of those arresting officers even have more hair than me. In Uganda, police arrest you, in hospitals we cannot get the necessary care or get medicine, and that's all because of a poor government policy.

-IDI, Uganda, MSM 20-24 years

In our country, one thing that you should know, homosexuality is illegal. So the fact that it is illegal, every hospital or public clinic-any place you go to-you find that they are neglected or made to look inferior.

-FGD, Uganda, female 20-24 years

Evidence shows a higher prevalence of HIV infection in the MSM subpopulation than in the general population. For example, in Egypt the estimated prevalence among MSM is 6 percent, compared with less than 0.1 percent in the general population. ${ }^{20}$ In Kenya, Nigeria, and South Africa, MSM are mentioned as vulnerable/key target groups within the national HIV/AIDS policies, but the policies in Egypt and Uganda are completely silent regarding MSM.

Sexual offense laws across these countries do not contain provisions for marital rape ${ }^{21}$ except in South Africa. This allowance for forced sex within the realm of marriage further marginalizes married young women and girls, limiting their negotiating power for safer-sex practice within marriage and violating their right to bodily integrity.

\section{YOUTH FOCUS IN POLICIES AND PROGRAM STRATEGIES}

Across all countries, national AIDS and related policies contain several noteworthy gaps and inconsistencies with regard to the treatment of youth and their particular vulnerabilities and needs. First, the definition of "youth" across all the study countries is problematic because most definitions are not in line with internationally accepted parameters. For example, Kenyan laws have various definitions for the various groups within the bracket known as "young persons." The new Constitution of 2010 defines a "child" as an individual who has not attained the age of 18 years, and a "youth" as someone who has attained the age of 18 years but has not attained the age of 35 years. The Age of Majority Act defines a person below the age of 18 as a "minor," and the Children Act, which is the law that deals with the protection of the rights of the child, defines a child as any human being under the age of 18. But in the area of marriage and divorce, the Matrimonial Causes Act gives different age categories for different races. It provides that an African child is a person who has not attained 16 years of age for males and 13 years for females. For other races, a child

\footnotetext{
${ }^{19}$ Smith et al. 2009. "Men who have sex with men and HIV in sub-Saharan Africa," Lancet 374: 416-22.

${ }^{20}$ Mumtaz, G. et al. 2011. "Are HIV epidemics among men who have sex with men emerging in the Middle East and North Africa? A systematic review and data synthesis," PLoS Med 8(8): e1000444. doi:10.1371/journal.pmed.1000444.

${ }^{21}$ See also Population Council-commissioned report on "The impact of HIV/AIDS on young people in Kenya: A critical analysis of legal, policy and programmatic responses," May 2012.
} 
is an unmarried person who has not attained the age of majority. The Hindu Marriage \& Divorce Act and the Marriage Act also have varied definitions. These inconsistencies in the definition of a child/youth ensure that there cannot be common protection for young people in Kenya with regard to marriage and divorce. This may have practical implications for the observance of the rights and welfare of children and youth.

Each of the study countries has developed a national HIV strategic plan that forms a basis for the HIV response. Overall, in the strategic plans, youth are targeted as part of the general population. Only Kenya and Senegal appear to pay special attention to youth-specific issues. In Senegal, for example, national guidelines in the fight against AIDS among youth have been developed for providers and stakeholders involved in the HIV response. The guidelines are shared with all stakeholders and are regularly updated. These guiding documents include: i) the passport for life, developed by the Youth Promotion Project (PPJ); ii) the guide of care for orphans and children who are made vulnerable by HIV/AIDS; iii) RH policies, standards, and protocols; iv) RH standards for adolescents/youth. Table 4 is a summary of the perspectives of each of the focal country's national strategic plans from the KIls performed with key stakeholders.

TABLE 4 Summary of national strategic plans, based on data from qualitative inquiries

\begin{tabular}{llllll}
\hline Egypt & Kenya & Nigeria & Senegal & South Africa & Uganda \\
\hline Well drafted but & Incorporate & Have some & Clear on stigma, & Address some & Address some \\
inadequate; most & youth needs but & youth-specific & have dimensions & youth needs but & youth needs but \\
of the policies & not specific on & provisions but & addressing youth & broad-based with & do not focus on \\
included are not & stigma, and have & treat youth as a & needs, but silent & no particular & marginalized \\
implemented & some gaps in & homogeneous & on MARPs, except focus on youth; & groups (e.g., sex \\
$\begin{array}{l}\text { (e.g., no sex } \\
\text { education }\end{array}$ & implementation. & population & for sex workers. & implementation & workers, LGBTIs), \\
curriculum in & & without a focus & & challenges are & many of whom \\
schools) and are & & on MARPs and & & also reported. & are young. \\
silent on MARPs. & vulnerable & & & \\
\hline
\end{tabular}

In the qualitative inquiries, informants acknowledged the existence of some youth-specific policies and guidelines.

Yeah, there are, there are policies. There is a policy, adolescent reproductive health policy. There is Uganda national HIV/AIDS policy. There are so many policies that I can't mention them all. -KII, Uganda

If there is anything the HIV/AIDS division has done very well it is in providing guidelines. Do you understand? If there is anything we have done very well is in providing guidelines.

- KII, Nigeria

In South Africa, the stakeholders interviewed did not report the existence of service guidelines for youth.

We don't have, and this is one of the things we have been working on. We need to look at adapting Project AIM and see how it can benefit the country.

-KII, South Africa

From the qualitative inquiries, a major concern expressed by stakeholders in Egypt, Kenya, Nigeria, and Uganda was not lack of youth-specific service-delivery guidelines but poor implementation as a result of unavailability of funds. 
There are plenty of guidelines and studies, but what matters is do people read them? The issue of reading is a difficult one in Egypt...some providers are trained while others are not.... This depends on availability of funds.

-KII, Egypt

Other concerns had to do with service providers' and program managers' awareness of existing guidelines. It was reported across the study sites that few service providers and program managers may be aware of the existence of the guidelines. This was attributed to poor dissemination of information.

I can say no because very few people are aware of these guidelines, and those who are aware may not even have access to these policies. The policies are developed, they are not made available to the public. For example, when you ask me, 'Do you have access to the national HIV/AIDS policy?' It may be lying in the offices, they are not online. We are talking about e-governance.

-KII, Uganda

Similarly, training on the guidelines was also said to be poorly executed since most service providers and program managers lacked the capacity and skill to handle some of the cases presented to them. This theme was mirrored in the narratives from Egypt, Kenya, Nigeria, South Africa and Uganda.

\section{LEGALLY BASED MANIFESTATIONS OF HIV-RELATED STIGMA AND DISCRIMINATION}

Progressive laws and policies regarding HIV-related stigma and discrimination are present across study countries, excluding Egypt, but there are also issues of poor enforcement, which is pervasive across all countries. In South Africa, the Equality Court was created to promote rights and access to justice for vulnerable groups, and it focuses specifically on complaints related to unfair discrimination based on a number of factors, including HIV status. The Labour Relations Act also prohibits unfair discrimination and has set clear boundaries that protect employees from being dismissed because of their HIV status and from being discriminated against in terms of employee benefits, promotions, staff training, and other work-related opportunities. The Employment Equity Act among other things prohibits unfair discrimination in "employment policy or practice." Section 6(1) of the Act specifically lists HIV status as a prohibited ground of discrimination, and discrimination on this ground is actionable. The Act prohibits an employer from testing employees and job applicants for HIV unless the Labour Court finds that such testing is justifiable and authorizes it. Despite these progressive provisions, challenges remain with the implementation. The State does not have enough capacity to enforce and educate people about the prevailing policies and legislation.

Uganda's current HIV/AIDS policy briefly mentions stigma and discrimination facing individuals living with HIV/AIDS (PLHA) as an issue that must be addressed as part of HIV prevention strategies but does not articulate concrete steps to doing so. A similar situation also exists in Senegal ${ }^{22}$ where the law on HIV/AIDS provides the right to nondiscrimination and the right to care and treatment services. It also prohibits forcible testing and screening.

Kenya's HIV and AIDS Prevention and Control Act has antidiscriminatory provisions including sections that outlaw discrimination in all aspects of life; prohibit compulsory testing in employment, marriage, admission into any educational institution, entry into or travel out of the country, etc.; require informed consent for testing; and ensure confidentiality of results. Qualitative inquiry respondents from Kenya especially noted that there are certain provisions that safeguard against abuses directed at HIV positive individuals. Moreover, it

${ }^{22}$ See Council-commissioned law and policy assessment "Study on addressing the HIV/AIDS vulnerability, stigma and discrimination of Senegal's youth," June 2012. 
was felt that the government has stepped up efforts to create awareness about HIV/AIDS in order to reduce stigma associated with the disease.

When a person abuses you that are HIV positive, he is supposed to sue and entitled to pay a fine.

FGD, Kenya, male 20-24

Government has improved awareness and education empowerment, hence people have started to accept one another.

FGD, Kenya, female 15-19

However, the legal context for protection against HIV-related discrimination for youth in Egypt and Nigeria seems to be more disenabling. In Nigeria, the lack of political will or motivation to pass a national law to protect PLHA is evidenced by the fact that the Anti-Stigma and Discrimination Bill has remained stagnant in the National Assembly for the past five years, although a few states have passed similarly protective legislature.

Even worse is the situation in Egypt, where people living with HIV face severe legally based stigma and discrimination. Although Egyptians are guaranteed the right to privacy and personal freedom by their constitution, some encroachment on individual privacy occurs in relation to HIV/AIDS testing and reporting. Certain population groups are required by law to take an HIV/AIDS test; these include drug users treated in rehabilitation units; prisoners; foreigners who plan to work, study, or train in Egypt; and men and women seeking employment in the Gulf states. The Medical Ethics Code preventing physicians from disclosing information about their patients can be breached; one instance is when the possibility of grave and certain damage to a third party is identified. Such a case includes the requirement for physicians to inform the relatives of PLHAs about their infection. The right to work for PLHA in certain occupations is also infringed upon; these occupations include handling food, joining the Armed Forces, joining general prosecution or administrative prosecution, or joining the Suez Canal Authority. The qualitative inquiries revealed little about the ways in which the government and civil society organizations in Egypt are addressing the stigma and discrimination faced by young people. 


\section{Chapter 4}

\section{Patterns in Sexual Behaviors and HIV-Related Discrimination}

\section{CROSS-COUNTRY SIMILARITIES}

\section{Risky Sexual Behaviors}

As explained in Chapter 2, for reasons of robustness of estimates and data availability on relevant variables, we analyzed youth exposure to risky sexual behaviors by assessing the earliness of their sexual debut, current sexual activity among the never-married aged 15-24, and engagement in multiple sexual partnerships among sexually active youth.

TABLE 5 Percentage of respondents aged 15-24 that had sex on or before age 15 , by country ${ }^{\mathrm{a}}$ and sex

\begin{tabular}{lrr}
\hline COUNTRY/Residence & Male & Female \\
\hline KENYA & 22.2 & 10.6 \\
Urban & 15.4 & 8.5 \\
Rural & 23.8 & 11.3 \\
NIGERIA & 5.8 & 15.7 \\
Urban & 5.0 & 7.6 \\
Rural & 6.2 & 20.2 \\
SENEGAL & 12.4 & 9.6 \\
Urban & 12.4 & 4.3 \\
Rural & 12.4 & 14.8 \\
SOUTH AFRICA & 12.2 & 6.0 \\
Urban & 13.4 & 5.5 \\
Rural & 9.8 & 7.0 \\
UGANDA & 12.2 & 15.3 \\
Urban & 15.5 & 11.8 \\
Rural & 11.4 & 16.2 \\
\hline
\end{tabular}

aData was not collected on this variable in the Egypt DHS.
Consistent with global findings, more young men than young women reported sexual debut before the age of 15, except in Nigeria and among rural Ugandan youth (Table 5). Male youth aged 15-24 in Kenya had the highest proportion of respondents self-reporting sex before age 15 (22.2 percent); Nigeria had the lowest (5.8 percent). Among females 15-24 years of age, Nigeria had the highest proportion (15.7 percent) reporting sex before age 15 while the lowest was in South Africa (6.0 percent). In Nigeria, rural respondents had higher proportions than urban respondents. For Senegal, South Africa and Uganda, while urban-based males seem clearly more likely to have had early sexual debut than their female peers, the female-male differentials among the rural-based respondents are less pronounced than the urban ones though in a reversed direction (except for South Africa).

Analysis of the data in relation to marriage also showed that among the sexually experienced or ever-married, more young women than young men were likely to report first sexual experience

at marriage. Across all countries, age groups, and residences (urban and rural) less than 10 percent of male youth reported having their first sexual experience at marriage. For female youth in ages 15-19 and 20-24, the highest proportion reporting first sex at marriage was in Senegal, while much lower proportions (below 5 percent) were documented for Kenya and South Africa.

Age at first sex is an important indicator of sexual risk because it determines the first exposure to sexual infection and is a risk factor for HIV infection. A 2005 study that explored early sexual debut among young 
men in rural South Africa revealed that these young men exhibited several risk factors for HIV infection. Young men reporting sexual debut before age 15 were more likely to not use condoms at first sex and more likely to have had multiple and casual sexual partners. ${ }^{23}$ Engaging in their first sexual encounter earlier among young men than among young women may be due to peer/societal pressure to demonstrate masculinity through sexual experience or prowess. ${ }^{24}$

Differences in the reporting of premarital sexual activity across gender may be the result of respondents tailoring their answers (over-reporting by men and under-reporting by women) and behaviors to the normative expectations of their respective gender. Gender norms shape early sexual experiences of both young men and women; male youths are encouraged to expand their sexual experiences, and their female counterparts are urged to exercise sexual restraint. ${ }^{25}$

Indeed, the same pattern emerges from the data on current sexual activity among never-married youth aged 15-24 (Table 6). The male respondents consistently reported much higher rates than females across the five countries except in Nigeria and urban Uganda.

\section{Multiple Sexual Partnerships}

Engagement in multiple sexual partnerships by sexually active respondents aged 15-24 is captured by the data presented in Figure 1. It seems from these that in line with societal gender norms, self-reporting of multiple sexual partnerships is relatively low among females (1.7-5.0 percent) and relatively high among males (15.0-30.1 percent) except in Egypt, where the data comes from a survey of urban street youth aged 10-19. Across the countries for which national data were available, more young men than women reported sex with multiple partners. The highest proportion of both male and female youth reporting multiple sexual partnerships was found in South Africa (excluding the Egyptian street youth data); the lowest rates for females were in Senegal, and the lowest rates for males were in Nigeria. Self-reporting of multiple sexual partnerships decreases slightly with age for females and increases slightly with age for males.
TABLE 6 Percentage of never-married respondents aged 15-24 that are currently sexually active by countrya and sex

\begin{tabular}{lrc}
\hline COUNTRY/Residence & Male & Female \\
\hline KENYA & 14.7 & 4.9 \\
Urban & 20.3 & 8.0 \\
Rural & 13.4 & 3.9 \\
NIGERIA & 11.2 & 14.1 \\
Urban & 11.4 & 14.5 \\
Rural & 11.1 & 13.8 \\
SENEGAL & 5.8 & 0.3 \\
Urban & 6.4 & 0.4 \\
Rural & 5.0 & 0.2 \\
SOUTH AFRICA & 34.1 & 24.5 \\
Urban & 35.8 & 26.7 \\
Rural & 30.6 & 20.4 \\
UGANDA & 9.7 & 6.5 \\
Urban & 7.9 & 8.9 \\
Rural & 10.1 & 5.7 \\
\hline
\end{tabular}

aData was not collected on this variable in the Egypt DHS.

\footnotetext{
${ }^{23}$ Harrison A., J. Cleland, E. Gouws, and J. Frohlich. 2005. "Early sexual debut among young men in rural South Africa: Heightened vulnerability to sexual risk," Sexually Transmitted Infections 81: 259-261.

${ }^{24}$ Varga, C.A. 2001. "The forgotten fifty percent: A review of sexual and reproductive health research and programs focused on boys and young men in sub-Saharan Africa," African Journal of Reproductive Health 5(3): 175-195.

${ }^{25}$ De Bruyn, M. 2000. "Gender, adolescents, and the HIV/AIDS epidemic: The need for comprehensive sexual and reproductive health responses. Expert group meeting on "The HIV/AIDS pandemic and its gender implications," 13-17 November. Windhoek, Namibia; Higgins, J.A., S. Hoffman, S.L. Dworkin. 2010. “Rethinking gender, heterosexual men, and women's vulnerability to HIV/AIDS," American Journal of Public Health 100: 435-445; Varga, C.A. 2001, Ibid.
} 
FIGURE 1 AMONG RESPONDENTS WHO WERE SEXUALLY ACTIVE IN THE PAST 12 MONTHS, PERCENTAGE REPORTING HAVING MULTIPLE SEXUAL PARTNERS, BY AGE, SEX, AND COUNTRY

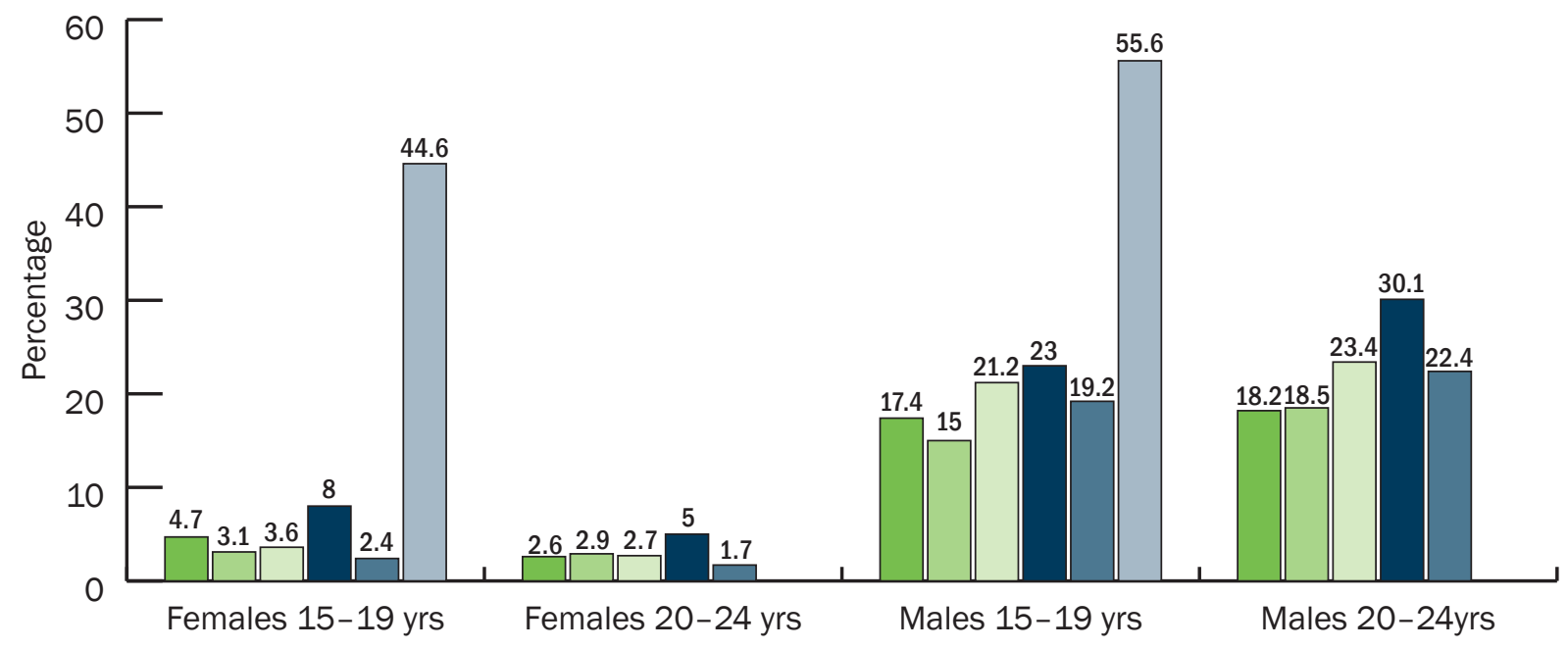

$\square$ Kenya $\square$ Nigeria $\square$ Uganda $\square$ South Africa $\square$ Senegal $\square$ Egypt

\section{Sexual Health-seeking Behaviors}

\section{Condom use}

Figure 2 shows that levels of condom use at last sex among young people with multiple partners varied from as low as 9.9 percent among female Ugandan youth aged 15-19 to 79.5 percent among male South African youth of the same age group. Within this multipartner sample, a greater proportion of young men than young women reported using condoms at last sex. Among countries with data for female youth of both age groups, South Africa had the highest proportion at 42.6 percent for each group.

FIGURE 2 AMONG RESPONDENTS WITH MULTIPLE SEXUAL PARTNERS IN THE PAST 12 MONTHS, PERCENTAGE REPORTING CONDOM USE AT LAST SEX, BY AGE, SEX, AND COUNTRY

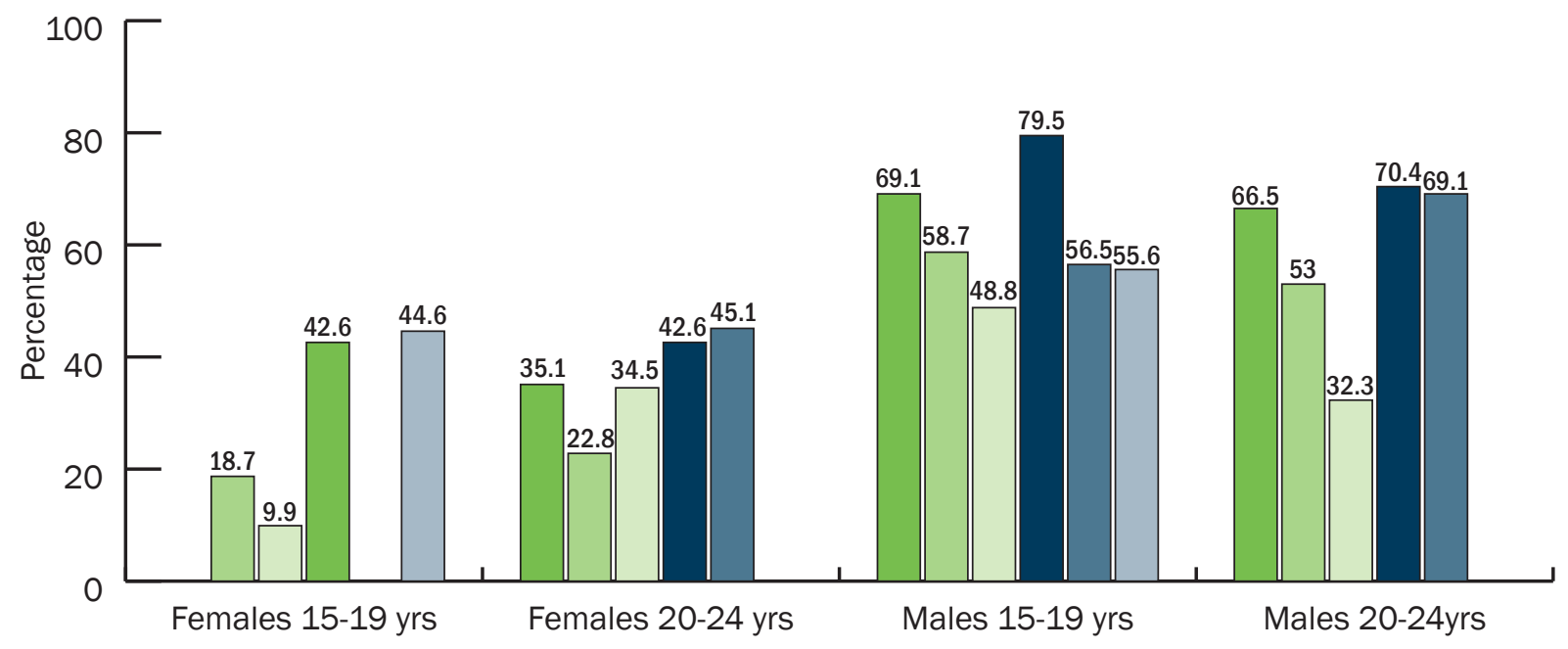

$\square$ Kenya $\square$ Nigeria $\square$ Uganda $\quad \square$ South Africa $\quad \square$ Senegal $\square$ Egypt 
TABLE 7 Percentage of respondents aged 15-24 who used a condom at last sex among those with multiple partners in the past 12 months by country and sex

\begin{tabular}{lcc}
\hline COUNTRY/Residence & Male & Female \\
\hline KENYA & 67.3 & 37.0 \\
Urban & $(71.2)$ & n.a \\
Rural & 65.6 & $(26.1)$ \\
NIGERIA & 54.2 & 21.3 \\
Urban & 63.9 & 31.5 \\
Rural & 47.4 & 14.7 \\
SENEGAL & 64.1 & 33.3 \\
Urban & 73.5 & $(53.9)$ \\
Rural & $(47.0)$ & $(12.9)$ \\
SOUTH AFRICA & 72.8 & 47.2 \\
Urban & 77.6 & 52.6 \\
Rural & $(59.3)$ & $(38.8)$ \\
UGANDA & 37.1 & 24.8 \\
Urban & $\mathrm{n} . \mathrm{a}$ & $\mathrm{n} . \mathrm{a}$ \\
Rural & 37.4 & 17.4 \\
\hline
\end{tabular}

a Data was not collected on this variable in the Egypt DHS; n.a.-represent estimates with sample sizes below 25 which are too small to be reliable. Estimates in parentheses represent sample sizes between 25-49 and should be interpreted with caution.
Although a close look at the data presented in Table 7 shows relatively high rates of condom use during last sex among young men and women with multiple partners across the five countries, much lower levels of condom use during such high-risk sex were reported among rural youth and among female youth relative to their urban and male peers respectively.

In Uganda, barriers to using condoms include lack of knowledge about how to use them, cost, availability (especially in rural areas), fears and distrust about condom effectiveness, and the perception that condoms themselves are a source of the HIV virus. ${ }^{26}$ Reasons given by Nigerian youth for nonuse of condoms with sexual partners were shyness, fear of implying a lack of trust in their sexual partner, and concern about their reputation in the eyes of their partners, parents, or society. ${ }^{27}$

The relatively low level of condom use among large categories of male and female African youth is particularly

worrisome given the high levels of high-risk sexual behavior. Increased condom messaging and distribution, and the inclusion of condom/sexual negotiation skills in youth sexuality education/HIV prevention programs, are essential.

\section{Uptake of HIV testing}

Figure 3 shows that uptake of HIV testing among young people remains relatively low in four of the five countries for which data were available (ranging from 1.1-42.8 percent) except in Kenya, where 68.9 percent of females aged 20-24 reported ever having an HIV test and receiving the result. Overall, Kenyan youth reported the highest rate of ever testing and receiving results; Senegalese youth reported the lowest level. More young women than men reported ever seeking and receiving HIV test results, except in Senegal and Nigeria, where the proportions were roughly equal. Among both sexes and both age groups (15-19 and 2024), young women in Kenya reported the highest rate of obtaining an HIV test and receiving the results (28.1 percent among 15-19-year-olds and 68.9 percent among 20-24-year-olds). The lowest rates among young women were found in Senegal (1.1 percent among 15-19-year-olds and 2.3 percent among 20-24-yearolds). A similar trend was observed across countries among young males from the same age groups. In Kenya, 22 percent of males aged 15-19 and 42.8 percent of males aged 20-24 reported testing for HIV and receiving results, whereas in Senegal the rates in the same categories were 1.2 percent and 2.4 percent, respectively.

\footnotetext{
${ }^{26}$ Neema, S., N. Musisi, and R. Kibombo. 2004. "Adolescent sexual and reproductive health in Uganda: A synthesis of research evidence." Occasional Report No. 14. New York: Alan Guttmacher Institute.

${ }^{27}$ Adedimeji, A.A., F.O. Omololu, and O. Odutolu. 2007. "HIV risk perception and constraints to protective behaviour among young slum dwellers in Ibadan, Nigeria," Journal of Health, Population, and Nutrition 25(2): 146-157; Owolabi, A. et al. 2005. "Sexual behaviour of secondary school adolescents in Ilesa, Nigeria: Implications for the spread of STIs including HIV/AIDS," Journal of Obstetrics and Gynaecology 25(2): 174-178.
} 


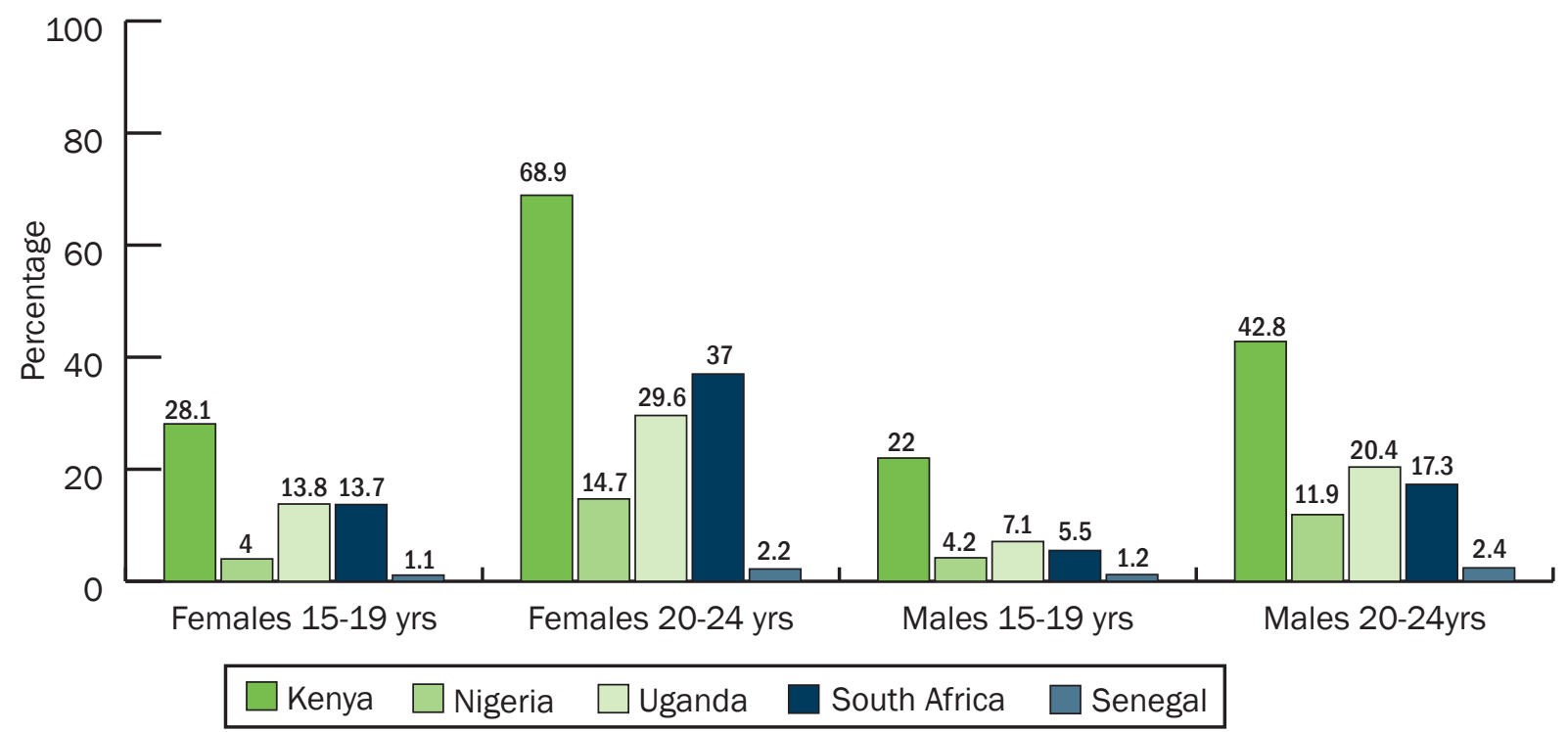

There is a clear disparity in HIV testing in terms of residence. More urban youth reported ever seeking and ever obtaining HIV-test results than did their rural counterparts, except among male Senegalese youth aged $15-19$, for whom the proportion was about the same (1.2 percent versus 1.1 percent) (data in this paragraph not shown). In all countries, more urban dwellers than rural dwellers also reported recent HIV testing, with the exception of Kenyan men aged 15-19, among whom rural proportions were higher than urban (14.5 percent versus 12.1 percent).

Factors that may contribute to the low uptake of voluntary counseling and testing (VCT) among youth are low awareness of VCT and places where VCT services are offered, low HIV risk perception, concerns about confidentiality, actual or perceived cost of VCT, fear of being positive, and stigmatization. ${ }^{28}$ The disparity between males and females with regard to uptake of VCT may be because pregnancy affords young women access to maternal/child services such as antenatal care, where VCT is one of several services provided. An additional factor may be men's poorer health-seeking behavior that results from gender norms that feminize illness and the seeking of formal medical care. ${ }^{29}$ Given the higher levels of self-reported high-risk behavior among young men, it is important for HIV prevention programmers to target interventions, especially VCT services, toward men, and to explore ways to increase male uptake of HIV services in general. Decreased access to VCT services and lower HIV knowledge in rural areas may be the reason for the urban-rural differences observed in VCT uptake. This highlights a need for program managers and policymakers to scale up and increase the geographic coverage of HIV services in these countries.

\footnotetext{
${ }^{28}$ Yahaya, L.A., A.A.G. Jimoh, and O.R. Balogun. 2010. "Factors hindering acceptance of HIV/AIDS voluntary counselling and testing (VCT) among youths in Kwara State, Nigeria," Journal of AIDS and HIV Research 2(7): 138-143; Bamidele, J.O., O.L. Abodunrin, and W.O. Adebimpe. 2009. "Sexual behaviour and risk of HIV/AIDS among adolescents in public secondary schools in Osogbo, Osun State, Nigeria," International Journal of Adolescent Medicine and Health 21(2): 387-394; Iyaniwura, C.A., O.J. Daniel, and 0.0. Adelowo. 2007. "Attitude of youths to sexual abstinence as a strategy for HIV prevention," Nigerian Medical Practitioner 52(2): 33-37; Ajuwon, A.J., F.0. Fawole, and K.O. Osungbade. 2011. "Experience and perpetration of violent behaviours among secondary school students in Ibadan, Nigeria," Sierra Leone Journal of Biomedical Research 3(1): 27-35; Ikechebelu, I.J., G.O. Udigwe, N. Ikechebelu, and L.C. Imoh. 2006. "The knowledge, attitude and practice of voluntary counselling and testing (VCT) for HIV/AIDS among undergraduates in a polytechnic in southeast, Nigeria," Nigerian Journal of Medicine 15(3): 245-249; Kabiru C.W., D. Beguy, J. Crichton, and E.M. Zulu. 2011. “HIV/AIDS among youth in urban informal (slum) settlements in Kenya: What are the correlates of and motivations for HIV testing?" BMC Public Health 11: 685

${ }^{29}$ Myburgh, H. 2011. The clinic as a gendered space: Masculinities, health-seeking behavior, and HIV \& AIDS. http://www. consultancyafrica.com/index.php?option=com content\&view=article\&id=760:the-clinic-as-a-gendered-space-masculinities-healthseeking-behaviour-and-hiv-a-aids\&catid=61:hiv-aids-discussion-papers\&ltemid=268. Accessed August 2012.
} 


\section{Comprehensive HIV Knowledge}

HIV awareness was high across all countries, with more than 80 percent of youth reporting that they have ever heard of HIV. However, less than 60 percent of youth had comprehensive knowledge of HIV/AIDS according to a composite of the five UNGASS indicators30 for HIV knowledge (Figure 4). Among young women, Kenyans had the highest levels of comprehensive knowledge, at 39 percent and 47.5 percent among youth aged 15-19 and 20-24, respectively, and their Senegalese counterparts had the lowest levels, at 17 percent and 20.1 percent, respectively. Similarly, young men in Kenya had the highest levels, and young men in Senegal the lowest. Across all countries, more young men than women had comprehensive knowledge. Additionally, more urban than rural youth displayed comprehensive HIV knowledge, and comprehensive HIV knowledge increased with age (not shown).

\section{FIGURE 4: PERCENTAGE OF RESPONDENTS REPORTING CORRECT ANSWERS ON ALL FIVE INDICATORS OF HIV KNOWLEDGE, BY AGE, SEX, AND COUNTRY}

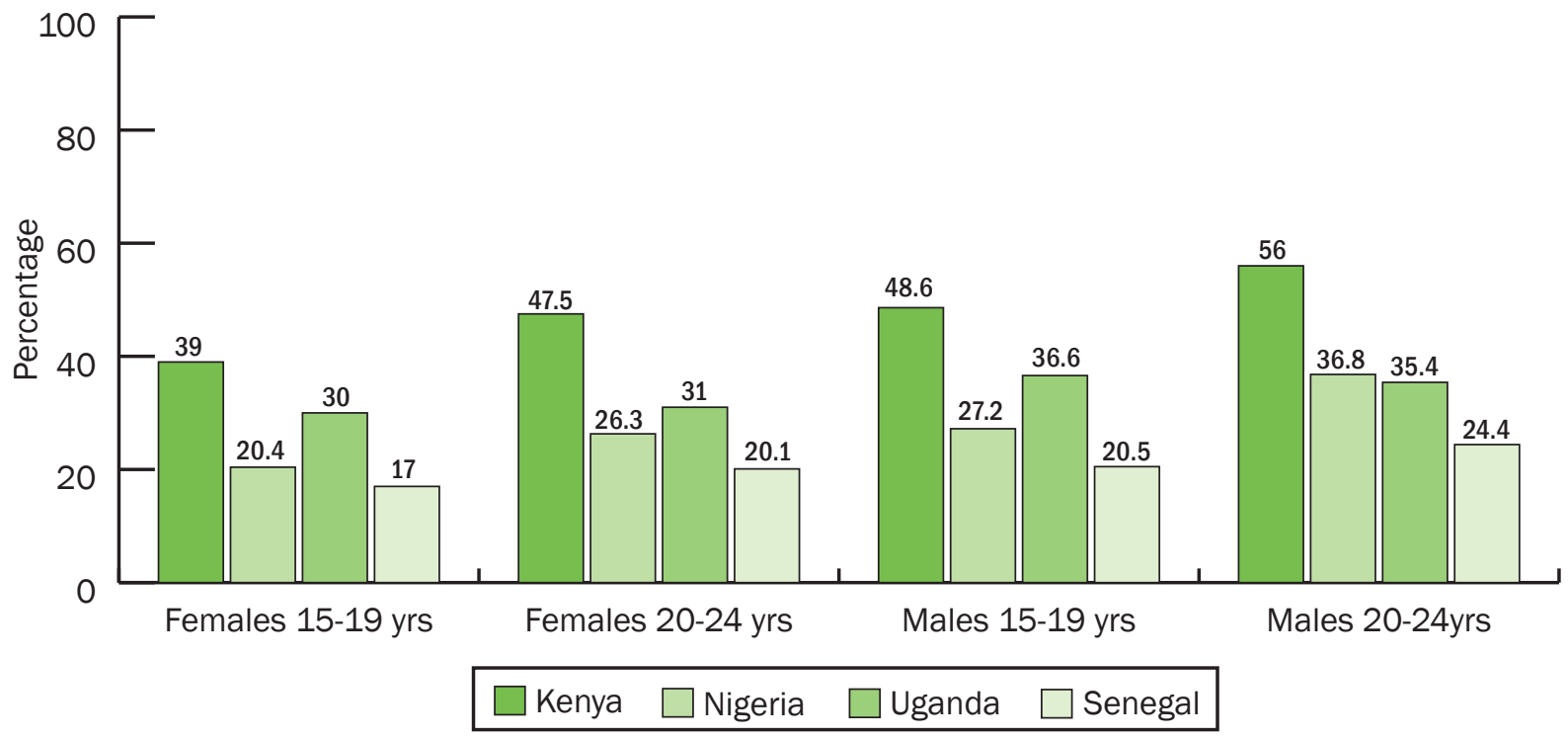

\section{Stigma and Discrimination}

According to UNAIDS, ${ }^{31}$ HIV/AIDS-related stigma can be described as a "process of devaluation" of people either living with or associated with HIV/AIDS, whereas discrimination follows stigma and is the unfair and unjust treatment of an individual based on his or her real or perceived HIV status. Stigma and discrimination breach fundamental human rights and can occur at a number of different levels, including economic, institutional, political, psychological, and social levels. A number of indicators have been used to measure stigma and discrimination that aim to identify an individual's level of stigma and discrimination, and their knowledge of the occurrence of stigma and discrimination. Stigma and discrimination play an enormous role in facilitating the spread of HIV by weakening prevention efforts, because fear of stigma and discrimination are the main reasons individuals refuse to be tested, disclose their sero-status, or take antiretroviral drugs.

\footnotetext{
30"Comprehensive knowledge" refers to knowing that consistent use of condoms during sexual intercourse and that having just one HIVnegative, faithful partner can reduce the chances of becoming infected with HIV; knowing that a healthy-looking person can have HIV; and rejecting the two most common local misconceptions about HIV transmission and prevention.

${ }^{31}$ Joint United Program on HIV/AIDS. “Stigma and discrimination factsheet." http://data.unaids.org/publications/Fact-Sheets03/fs_ stigma_discrimination_en.pdf. Accessed June 2012.
} 
Overall, relatively high proportions of young people (>25 percent) reported that they would want family members to keep their HIV status a secret. For both male and female youth, Senegal had the highest proportions of youth who would want a family member to keep HIV status secret (females aged 15-19: 63.8 percent, and aged 20-24: 63.5 percent; males aged 15-19: 53 percent, and aged 20-24: 51.9 percent). South Africa had the lowest proportion among female youth (aged 15-19: urban 38.0 percent, rural 38.4 percent; aged 20-24: urban 38.1 percent, rural 37.4 percent), and Kenya had the lowest proportion among male youth (aged 15-19: 37.9 percent; aged 20-24: 26.7 percent). The low level observed in South Africa may reflect direct impact of the South African government's campaign against HIV and its support for increasing HIV knowledge, counseling, and treatment. In Senegal, HIV/AIDS is strongly linked to lifestyle and perceived morality32, and this may explain the high level of secrecy observed among both males and females. More urban than rural youth reported secrecy about HIV status in all countries except South Africa and Uganda. This divide may reflect the scale and coverage of anti-stigma efforts, although further research is needed. Except for Senegal, respondents aged 15-19 were more tolerant of family members being HIV positive than were those aged 20-24. Though one might argue that older respondents should be more knowledgeable and have a less stigmatizing attitude, there are indications that knowledge may not have changed attitudes. Furthermore, younger age groups may have stronger familial attachment and less societal influence on their behaviors and attitudes.

\section{FACTORS IN THE SEXUAL-RISK AND HEALTH-SEEKING BEHAVIORS OF YOUTH}

\section{Risky Sexual Behaviors}

The logistic regression analysis (Table 8 ) showed being female to be significantly inversely associated with early sexual debut in Kenya and Senegal, whereas in Nigeria, females aged 15-24 were significantly more likely to have had sex on or before age 15 than males of the same age group (RRR: 1.276). However, across the five countries, possession of any form of higher education was significantly associated with much reduced likelihood of early sexual debut relative to respondents with no formal education (RRRs <0.330), except in Senegal. A broadly similar inverse correlation was established between household wealth status of youth and early sexual debut in all five countries (except Kenya). On the other hand, being currently married is clearly significantly associated with early sexual debut in all countries relative to being never-married (Kenya-RRR: 2.908, Nigeria-RRR: 5.222, Senegal-RRR: 12.408, Uganda-RRR: 3.380, and South Africa-RRR: 1.501).

For current sexual activity among never-married youth aged 15-24 (Table 9), being aged 20-24 (compared to 15-19) was significantly associated with this behavior in all five countries (RRRs of around 1.20) as was being currently employed (relative to 'Not working') with RRRs > 1.53, except in South Africa where this variable did not turn out to be statistically significant. By contrast, being female was uniformly associated with less likelihood of being sexually active among never-married youth across the five countries. Interestingly, the household wealth status variable was shown to be significantly associated with less likelihood of current sexual activity among unmarried youth in only three of the five countries (Kenya, Nigeria and Senegal), and even so, not consistently across levels of the wealth index.

\footnotetext{
${ }^{32}$ Ansari, D.A and A. Gaestel. 2010. "Senegalese religious leaders' perceptions of HIV/AIDS and implications for challenging stigma and discrimination," Culture, Health, and Sexuality 12(6): 633-648.
} 
TABLE 8 Relative risk ratios from logistic regression analysis of predictors of sexual debut on or before age 15 by country

\begin{tabular}{|c|c|c|}
\hline Characteristic & $\begin{array}{c}\text { Relative risk ratio } \\
\text { (RRR) }\end{array}$ & $\begin{array}{c}\text { Standard error } \\
\text { (se) }\end{array}$ \\
\hline \multicolumn{3}{|l|}{ KENYA } \\
\hline \multicolumn{3}{|l|}{ Gender (Ref is Male) } \\
\hline Female & $0.328 * * *$ & 0.037 \\
\hline \multicolumn{3}{|l|}{ Education (Ref is No education) } \\
\hline Any secondary & $0.433 * * *$ & 0.092 \\
\hline Any higher & $0.227 * * *$ & 0.700 \\
\hline \multicolumn{3}{|l|}{ Marital status (Ref is Never married) } \\
\hline Currently married & $2.908 * * *$ & 0.386 \\
\hline Separated, divorced, or widowed & $1.769 * * *$ & 0.319 \\
\hline \multicolumn{3}{|l|}{ Occupation (Ref is Not working) } \\
\hline Currently working & $1.315 * * *$ & 0.126 \\
\hline \multicolumn{3}{|l|}{ SENEGAL } \\
\hline \multicolumn{3}{|l|}{ Gender (Ref is Male) } \\
\hline Female & $0.434 * * *$ & 0.069 \\
\hline \multicolumn{3}{|l|}{ Marital status (Ref is Never married) } \\
\hline Currently married & $12.408 * * *$ & 1.476 \\
\hline Separated, divorced, or widowed & $8.295 * * *$ & 2.037 \\
\hline \multicolumn{3}{|l|}{ Wealth (Ref is Wealth quintile 1)) } \\
\hline Wealth quintile 2 & $0.696 * * *$ & 0.061 \\
\hline Wealth quintile 3 & $0.526 * * *$ & 0.101 \\
\hline Wealth quintile 4 & $0.292 * * *$ & 0.043 \\
\hline Wealth quintile 5 & $0.240 * * *$ & 0.048 \\
\hline \multicolumn{3}{|l|}{ UGANDA } \\
\hline \multicolumn{3}{|l|}{ Education (Ref is No education) } \\
\hline Any primary & $0.698 * *$ & 0.123 \\
\hline Any secondary & $0.526 * * *$ & 0.101 \\
\hline Any higher & $0.327 * * *$ & 0.091 \\
\hline \multicolumn{3}{|l|}{ Marital status (Ref is Never married) } \\
\hline Currently married & $3.380 * * *$ & 0.307 \\
\hline Separated, divorced, or widowed & $2.623 * * *$ & 0.380 \\
\hline \multicolumn{3}{|l|}{ Occupation (Ref is Not working) } \\
\hline Currently working & $1.408 * * *$ & 0.145 \\
\hline \multicolumn{3}{|l|}{ Wealth (Ref is Wealth quintile 1 ) } \\
\hline Wealth quintile 5 & $1.523 * *$ & 0.257 \\
\hline \multicolumn{3}{|l|}{ SOUTH AFRICA } \\
\hline \multicolumn{3}{|l|}{ Education (Ref is No education) } \\
\hline Any higher & $0.286 * * *$ & 0.152 \\
\hline \multicolumn{3}{|l|}{ Marital status (Ref is Never married) } \\
\hline Currently married & $1.501 * *$ & 0.289 \\
\hline Separated, divorced, or widowed & $2.292 * * *$ & 0.606 \\
\hline \multicolumn{3}{|l|}{ Wealth (Ref is Wealth quintile 1 ) } \\
\hline Wealth quintile 4 & $0.459 * * *$ & 0.113 \\
\hline Wealth quintile 5 & $0.322 * * *$ & 0.114 \\
\hline NIGERIA & & \\
\hline Gender (Ref is Male) & & \\
\hline Female & $1.276 * * *$ & 0.098 \\
\hline Residence (Ref is Rural) & & \\
\hline Urban & $1.177 * * *$ & 0.046 \\
\hline Education (Ref is No education) & & \\
\hline Any primary & $0.562 * * *$ & 0.039 \\
\hline Any secondary & $0.514 * * *$ & 0.035 \\
\hline Any higher & $0.204 * * *$ & 0.035 \\
\hline Marital status (Ref is Never married) & & \\
\hline Currently married & $5.222 * * *$ & 0.348 \\
\hline Separated, divorced, or widowed & $2.421 * * *$ & 0.286 \\
\hline Wealth (Ref is Wealth quintile 1) & & \\
\hline Wealth quintile 4 & $0.849 * * *$ & 0.069 \\
\hline Wealth quintile 5 & $0.567 * * *$ & 0.023 \\
\hline
\end{tabular}

$* * *$ Significant at $p<0.01 . * *$ Significant at $p<0.05$. Ref $=$ Reference category. 
TABLE 9 Relative risk ratios from logistic regression analysis of predictors of current sexual activity among never-married youth aged $15-24$ by country

\begin{tabular}{|c|c|c|}
\hline Characteristic & $\begin{array}{l}\text { Relative risk ratio } \\
\text { (RRR) }\end{array}$ & $\begin{array}{c}\text { Standard error } \\
\text { (se) }\end{array}$ \\
\hline \multicolumn{3}{|l|}{ KENYA } \\
\hline \multicolumn{3}{|c|}{ Age (Ref is $15-19$ years) } \\
\hline 20-24 years & $1.183 * * *$ & 0.033 \\
\hline \multicolumn{3}{|l|}{ Gender (Ref is Male) } \\
\hline Female & $0.154 * * *$ & 0.027 \\
\hline \multicolumn{3}{|c|}{ Education (Ref is No education) } \\
\hline Any higher & $2.796 * *$ & 1.352 \\
\hline \multicolumn{3}{|c|}{ Occupation (Ref is Not working) } \\
\hline Currently working & $1.628 * * *$ & 0.288 \\
\hline \multicolumn{3}{|c|}{ Wealth (Ref is Wealth quintile 1 ) } \\
\hline Wealth quintile 5 & $0.536 * *$ & 0.143 \\
\hline \multicolumn{3}{|l|}{ SENEGAL } \\
\hline \multicolumn{3}{|c|}{ Age (Ref is $15-19$ years) } \\
\hline $20-24$ years & $1.230 * * *$ & 0.032 \\
\hline \multicolumn{3}{|l|}{ Gender (Ref is Male) } \\
\hline Female & $0.177 * * *$ & 0.041 \\
\hline \multicolumn{3}{|c|}{ Education (Ref is No education) } \\
\hline Any primary & $1.839 * * *$ & 0.360 \\
\hline \multicolumn{3}{|c|}{ Occupation (Ref is Nor working) } \\
\hline Currently working & $1.666 * *$ & 0.333 \\
\hline \multicolumn{3}{|c|}{ Wealth (Ref is Wealth quintile 1)) } \\
\hline Wealth quintile 2 & $0.591 * *$ & 0.147 \\
\hline Wealth quintile 4 & $0.207 * * *$ & 0.076 \\
\hline Wealth quintile 5 & $0.125 * * *$ & 0.052 \\
\hline \multicolumn{3}{|l|}{ UGANDA } \\
\hline \multicolumn{3}{|c|}{ Age (Ref is $15-19$ years) } \\
\hline 20-24 years & $1.231 * * *$ & 0.030 \\
\hline \multicolumn{3}{|l|}{ Gender (Ref is Male) } \\
\hline Female & $0.166 * * *$ & 0.025 \\
\hline \multicolumn{3}{|c|}{ Education (Ref is No education) } \\
\hline Any higher & $3.455 * * *$ & 1.554 \\
\hline \multicolumn{3}{|c|}{ Occupation (Ref is Not working) } \\
\hline Currently working & $2.148 * * *$ & 0.501 \\
\hline \multicolumn{3}{|c|}{ SOUTH AFRICA } \\
\hline \multicolumn{3}{|c|}{ Age (Ref is $15-19$ years) } \\
\hline 20-24 years & $1.244 * * *$ & 0.024 \\
\hline \multicolumn{3}{|l|}{ Gender (Ref is Male) } \\
\hline Female & $0.639 * *$ & 0.113 \\
\hline \multicolumn{3}{|c|}{ Residence (Ref is Rural) } \\
\hline Urban & $0.881 * *$ & 0.054 \\
\hline NIGERIA & & \\
\hline Age (Ref is $15-19$ ye & & \\
\hline 20-24 years & $1.180 * * *$ & 0.014 \\
\hline Gender (Ref is Male) & & \\
\hline Female & $0.524 * * *$ & 0.040 \\
\hline Education (Ref is No & & \\
\hline Any primary & $1.794 * * *$ & 0.219 \\
\hline Any secondary & $3.761 * * *$ & 0.427 \\
\hline Any higher & $5.399 * * *$ & 0.846 \\
\hline Occupation (Ref is Nc & & \\
\hline Currently working & $1.533 * * *$ & 0.100 \\
\hline Wealth (Ref is Wealth & & \\
\hline Wealth quintile 2 & $0.765 * *$ & 0.093 \\
\hline
\end{tabular}

$* * *$ Significant at $p<0.01 . * *$ Significant at $p<0.05$. Ref $=$ Reference category. 
Going by the findings from the multivariate analysis of factors associated with risky sexual behaviors presented above, it is striking that quite a number of socio-economic variables that are theoretically expected to be strongly predictive of youth engagement in risky sexual behaviors did not turn out to be consistently so across the five countries for which relevant data were available. Particularly noteworthy are urban residence which was significantly associated with early sexual debut in Nigeria only, and being currently employed which turned out to be significantly associated with early sexual debut in Uganda and Kenya only.

It is however also noteworthy that for current sexual activity among never-married youth, three factors-being 20-24, having any form of higher education, and being currently employed-were significantly predictive of this outcome in all five countries except South Africa. These results may be due to more disposable income and relative freedom from parental control and sociocultural restraints associated with a higher educational status, being employed and being older, and consequently possessing more capacity and freedom to engage in activities that may lead to exposure to high-risk sex.

\section{Condom use during last sex among those with multiple partners}

The regression estimates presented in Table 10 show that in Kenya (RRR: 0.401), Nigeria (RRR: 0.558) and South Africa (RRR: 0.409), female youth involved in multiple sexual partnerships were significantly less likely to report using condoms during their last sexual intercourse. This pattern may be attributable to young women's relatively weaker bargaining power during sex, either due to the association of condoms with infidelity, or being offered more money or material goods when engaged in inter-generational sex. Age and education, on the other hand, showed very strong positive association with condom use by youth with multiple sexual partners across four of the five countries for which data were collected on this variable. Thus, in Kenya, Nigeria, Senegal and Uganda, youth with any form of higher education were respectively about 3 , 10, 6 and 5 times more likely to report using condoms during their last sexual intercourse than youth with no formal education.

It seems therefore in the light of the findings presented earlier on factors associated with engagement in risky sexual behaviors, that although higher educational status was associated with higher likelihood of engaging in high-risk sex, it was also associated with higher use of condoms, but to a slightly lesser degree. It is also notable that in four of the five countries (Nigeria, Uganda, Senegal and South Africa), being currently or previously married was significantly associated with reduced likelihood of condom use within multiple sexual partnerships. This calls for targeted condom messaging for this category of young people in Africa. 
TABLE 10 Relative risk ratios from logistic regression analysis of predictors of condom use during last sex among sexually active youth who had multiple partners in the past 12 months by country

\begin{tabular}{|c|c|c|}
\hline Characteristic & Relative risk ratio (RRR) & Standard error (se) \\
\hline \multicolumn{3}{|l|}{ KENYA } \\
\hline \multicolumn{3}{|l|}{ Age (Ref is $15-19$ years) } \\
\hline 20-24 years & $1.131 * *$ & 0.052 \\
\hline \multicolumn{3}{|l|}{ Gender (Ref is Male) } \\
\hline Female & $0.401 * *$ & 0.148 \\
\hline \multicolumn{3}{|l|}{ Education (Ref is No education) } \\
\hline Any higher & $3.165 * * *$ & 0.325 \\
\hline \multicolumn{3}{|l|}{ NIGERIA } \\
\hline \multicolumn{3}{|l|}{ Age (Ref is $15-19$ years) } \\
\hline $20-24$ years & $1.120 * * *$ & 0.033 \\
\hline \multicolumn{3}{|l|}{ Gender (Ref is Male) } \\
\hline Female & $0.558 * * *$ & 0.069 \\
\hline \multicolumn{3}{|l|}{ Education (Ref is No education) } \\
\hline Any primary & $3.385 * *$ & 0.966 \\
\hline Any secondary & $7.252 * * *$ & 1.901 \\
\hline Any higher & $9.869 * * *$ & 3.332 \\
\hline \multicolumn{3}{|l|}{ Marital status (Ref is Never married) } \\
\hline Currently married & $0.111 * * *$ & 0.034 \\
\hline Separated, divorced, or widowed & $0.183 * * *$ & 0.049 \\
\hline \multicolumn{3}{|l|}{ Residence (Ref is Rural) } \\
\hline Urban & $1.223 * *$ & 0.095 \\
\hline \multicolumn{3}{|c|}{ Occupational status (Ref is Not working) } \\
\hline Currently working & $1.429 * *$ & 0.187 \\
\hline \multicolumn{3}{|l|}{ Wealth index (Ref is Wealth quintile 1 ) } \\
\hline Wealth quintile 2 & $1.994 * *$ & 0.591 \\
\hline Wealth quintile 3 & $2.200 * *$ & 0.716 \\
\hline Wealth quintile 4 & $3.009 * * *$ & 1.168 \\
\hline Wealth quintile 5 & $3.632 * * *$ & 0.014 \\
\hline \multicolumn{3}{|l|}{ SENEGAL } \\
\hline \multicolumn{3}{|l|}{ Age (Ref is $15-19$ years) } \\
\hline $20-24$ years & $1.153 * *$ & 0.025 \\
\hline \multicolumn{3}{|l|}{ Education (Ref is No education) } \\
\hline Any secondary & $6.922 * * *$ & 2.417 \\
\hline Any higher & $5.979 * * *$ & 3.685 \\
\hline \multicolumn{3}{|l|}{ Marital status (Ref is Never married) } \\
\hline Currently married & $0.028 * * *$ & 0.014 \\
\hline Separated, divorced, or widowed & $0.131 * * *$ & 0.074 \\
\hline \multicolumn{3}{|l|}{ SOUTH AFRICA } \\
\hline \multicolumn{3}{|l|}{ Gender (Ref is Male) } \\
\hline Female & $0.409 * * *$ & 0.091 \\
\hline \multicolumn{3}{|l|}{ Marital status (Ref is Never married) } \\
\hline Currently married & $0.324 * * *$ & 0.067 \\
\hline Separated, divorced, or widowed & $0.174 * * *$ & 0.068 \\
\hline \multicolumn{3}{|l|}{ Residence (Ref is Rural) } \\
\hline Urban & $0.874 * *$ & 0.072 \\
\hline UGANDA & & \\
\hline Age (Ref is $15-19$ years) & & \\
\hline $20-24$ years & $2.101 * *$ & 0.608 \\
\hline Education (Ref is No education) & & \\
\hline Any higher & $5.423 * *$ & 3.631 \\
\hline Residence (Ref is Rural) & & \\
\hline Urban & $0.667 * * *$ & 0.084 \\
\hline Marital status (Ref is Never married) & & \\
\hline Currently married & $0.147 * * *$ & 0.033 \\
\hline Separated, divorced, or widowed & $0.250 * *$ & 0.104 \\
\hline
\end{tabular}

$* * *$ Significant at $p<0.01 . * *$ Significant at $p<0.05$. Ref $=$ Reference category. Note: Egypt is excluded for lack of data. 


\section{Factors Associated with Comprehensive Knowledge of HIV}

In all four countries (Kenya, Nigeria, Senegal and Uganda) for which available data allowed logistic regression on display of comprehensive knowledge of HIV by youth (Table 11), education and household wealth index were consistently significantly predictive of this outcome. For example, youth with any form of higher education in Kenya, Nigeria, Senegal and Uganda were respectively 20.5, 3.8, 4.1 and 5.7 times more likely to display comprehensive knowledge of HIV than their peers with no formal education net of the effect of the other variables in the regression model (age, gender, occupational status, household wealth status, and ruralurban residence). Similarly, though of smaller magnitude, 15-24 year-olds resident in the richest households (wealth quintile 5) in Kenya, Nigeria, Senegal and Uganda were respectively 2.2, 2.1, 4.0, and 1.6 times more likely to report comprehensive knowledge of HIV than their peers from the poorest households.

It is also noteworthy that older youth (aged 20-24) in Kenya (RRR: 1.065), Nigeria (RRR: 1.079), and Senegal (RRR: 1.108) were slightly more likely to display comprehensive knowledge of HIV than youth aged 15-19 years. Female youth, on the other hand, were less likely to report comprehensive knowledge of HIV only in Nigeria. Overall, these patterns suggest the need to target HIV prevention education efforts toward socially disadvantaged youth across Africa as knowledge greatly influences behavior, beliefs and perceptions. 
TABLE 11 Relative risk ratios from logistic regression analysis of predictors of comprehensive knowledge of HIV among respondents by country

\begin{tabular}{|c|c|c|}
\hline Characteristic & Relative risk ratio (RRR) & Standard error (se) \\
\hline \multicolumn{3}{|l|}{ KENYA } \\
\hline \multicolumn{3}{|c|}{ Age (Ref is $15-19$ years) } \\
\hline 20-24 years & $1.065 * * *$ & 0.020 \\
\hline \multicolumn{3}{|c|}{ Education (Ref is No education) } \\
\hline Any primary & $4.609 * * *$ & 1.571 \\
\hline Any secondary & $8.886 * * *$ & 3.115 \\
\hline Any higher & $20.515 * * *$ & 8.397 \\
\hline \multicolumn{3}{|c|}{ Wealth index (Ref is Wealth Quintile 1) } \\
\hline Wealth quintile 2 & $1.449 * * *$ & 0.182 \\
\hline Wealth quintile 3 & $1.509 * * *$ & 0.186 \\
\hline Wealth quintile 5 & $2.234 * * *$ & 0.422 \\
\hline \multicolumn{3}{|l|}{ NIGERIA } \\
\hline \multicolumn{3}{|c|}{ Age (Ref is $15-19$ years) } \\
\hline 20-24 years & $1.079 * * *$ & 0.009 \\
\hline \multicolumn{3}{|l|}{ Gender (Ref is Male) } \\
\hline Female & $0.694 * * *$ & 0.041 \\
\hline \multicolumn{3}{|c|}{ Education (Ref is No education) } \\
\hline Any primary & $1.486 * * *$ & 0.136 \\
\hline Any secondary & $2.554 * * *$ & 0.228 \\
\hline Any higher & $3.801 * * *$ & 0.466 \\
\hline \multicolumn{3}{|c|}{ Wealth index (Ref is Wealth quintile 1 ) } \\
\hline Wealth quintile 2 & $1.413 * * *$ & 0.110 \\
\hline Wealth quintile 3 & $1.627 * * *$ & 0.142 \\
\hline Wealth quintile 4 & $1.861 * * *$ & 0.179 \\
\hline Wealth quintile 5 & $2.139 * * *$ & 0.231 \\
\hline \multicolumn{3}{|l|}{ SENEGAL } \\
\hline \multicolumn{3}{|c|}{ Age (Ref is $15-19$ years) } \\
\hline 20-24 years & $1.108 * * *$ & 0.016 \\
\hline \multicolumn{3}{|c|}{ Education (Ref is No education) } \\
\hline Any primary & $1.465 * * *$ & 0.143 \\
\hline Any secondary & $4.257 * * *$ & 0.412 \\
\hline Any higher & $4.061 * * *$ & 1.486 \\
\hline \multicolumn{3}{|c|}{ Wealth index (Ref is Wealth quintile 1 ) } \\
\hline Wealth quintile 2 & $1.840 * * *$ & 0.235 \\
\hline Wealth quintile 3 & $2.083 * * *$ & 0.272 \\
\hline Wealth quintile 4 & $3.171 * * *$ & 0.477 \\
\hline Wealth quintile 5 & $4.038 * * *$ & 0.595 \\
\hline \multicolumn{3}{|l|}{ UGANDA } \\
\hline \multicolumn{3}{|c|}{ Education (Ref is No education) } \\
\hline Any primary & $2.193 * * *$ & 0.423 \\
\hline Any secondary & $6.019 * * *$ & 1.236 \\
\hline Any higher & $5.719 * * *$ & 1.544 \\
\hline \multicolumn{3}{|c|}{ Wealth index (Ref is Wealth quintile 1 ) } \\
\hline Wealth quintile 5 & $1.605 * * *$ & 0.244 \\
\hline
\end{tabular}

$* * *$ Significant at $p<0.01$. Ref $=$ Reference category. Note: South Africa and Egypt are excluded. 


\section{Chapter 5 \\ HIV Youth-Focused Responses at the Individual, Institutional, and Policy Levels}

\section{SIX-COUNTRY OVERVIEW}

Youth-focused responses across study countries and at the individual, institutional, and policy levels are currently insufficient to tackle the HIV-related vulnerabilities of young people described in the previous chapters.

At the individual level, youth lack access to appropriate SRH information and confidential, low-cost, and stigma-free SRH services. Institutional responses are hampered by sociocultural sensitivities to youth premarital sexual activity, inadequate provision of sexuality education, and limited geographic and target population reach of current youth-focused programming. There continue to be few youth-specific policy provisions, which are hindered by weak political commitments and inadequate resourcing for implementation.

Egypt's response to the issue of HIV among young people stands out from the other study countries. There is a complete policy silence on the possibility of premarital sexual activity among young people evidenced by the decision not to collect information on sexual behavior among youth in the 2008 Egypt DHS. Due to the low national prevalence, HIV is not perceived as a real threat, and unlike the other study countries that have adopted multisectoral responses, Egypt's response is housed completely in the health sector, which may explain the country's neglect of the social/structural issues that drive the epidemic in favor of a strictly biomedical strategy for disease containment. Finally, according to Egyptian law, funds from external donors must be given directly to the Egyptian government, which is responsible for distributing such resources among implementing organizations. This has implications for the diversity and reach of the interventions implemented and has had negative consequences for the country's most at-risk populations (IDUs, MSM, sex workers) who are at higher risk of HIV infection yet face hostility and neglect from policymakers.

\section{COMMONALITIES AND SPECIFICITIES}

\section{Individual-level Concerns and Responses}

At the individual level, sexual and reproductive health is considered a significant need among youth. Concerns and anxieties about contracting HIV and STIs, sexual violence, unwanted pregnancies, and abortion have led the majority of the youth interviewed to openly state that SRH is a major need among young people. Respondents felt strongly about the links between the risk of acquiring HIV and risky sexual behavior, poor communication skills, and sexual violence.

There is HIV/AIDS and some fear to go to be tested. Some (young people) may be in a relationship and they don't have that knowledge to talk about relationships. They can't sit down and talk about HIV/AIDS, they fear.

FGD, Kenya, female 18-24 
Another thing which I feel is that...you do not have to have had sex to get an STI or HIV or get pregnant. Maybe you were raped and you see, that is not your fault but it was just bad luck that you get HIV or STI.

FGD, Kenya, female 20-24

For me, the problems are sexually transmitted infection and HIV.

FGD, Nigeria, male 15-19

Despite the fact that youth consider their sexual and reproductive health to be a priority, many feel powerless to adequately respond to HIV and SRH vulnerabilities because of inadequate knowledge, service-provider issues, setup of services, and livelihood struggles.

Inadequate knowledge about HIV and SRH issues appeared to affect the uptake of certain SRH services, as many participants expressed their intent to use or not use a service based on the information available. Many felt that poor negotiating skills, lack of condom use, and increased risk of unintended pregnancy occurred because of lack of adequate information.

Me, I can say that they (youth) lack the information like maybe information on family planning. If it is a girl, and she does not know that she can protect herself, then she can become pregnant.

FGD, Kenya, female 20-24

And the boy does not know that he can protect himself by using a condom so that he does not make someone pregnant or get an STI. There are some boys who don't know that they can use things like condoms, so that they do not get those STD diseases.

FGD, Kenya, female 20-24

Young people know about HIV, young people know about how to prevent, the importance, but young people lack the actual negotiation power to use condoms. Young people lack the negotiation power to actually ask partners to go and test for HIV when all this comes up.

KII, Uganda, national HIV program manager

Young people are not aware of these centers. When they need services, they do not always know what to do or where to go.

FGD, Senegal, male 20-24

It (an HIV prevention program) is not really happening in this country for out-of-school youth who harbor a lot of misconceptions and are not aware of SRH and HIV issues.... Sixty percent are not aware.

FGD, Nigeria, male 15-19

Contrary to expectations, sexually active youths tend to have a greater fear of pregnancy than of HIV.

I have never seen any school promoting the use of condoms.... Services focus more on HIV, which young people are not as afraid of as pregnancy. Yes, some of them don't see it as a real fear.

IDI, female orphan, Nigeria

There are some youths who believe that when you are in teenage stage you have to do something to prove to your boyfriend that you love him. You won't care if he is positive or has other issues. She doesn't think of any issue apart from pregnancy. After doing sex they just go to the chemist to get E-pills and that's all.

FGD, Kenya, female PLHA 15-19 
Respondents often mentioned service-provider issues such as stigmatizing attitudes and a lack of confidentiality and competence as deterrents for many young people to seek HIV and SRH services, especially in public-health facilities.

There are so many health problems facing young people. One that I can talk of now is sexually transmitted infection, because once they have the infection, to access treatment is always very difficult for them. Not that facilities are not there, but young people are not comfortable going to such facilities to present such ailment to care providers who could be their parents' friends.

FGD, Nigeria, female 15-19

They lack somewhere where they can go to get treatment, that is somewhere which is...how can I say it?... I mean somewhere where they are safe, so even if it is that sexual infection that you are going to get treatment for, no one will go to spread your story out there. So there they lack... is it called confidentiality...they don't have that. They don't keep your secret. I don't know, if you go there, they will spread your stories out there. Maybe it's because they know you, but I don't know why.

FGD, Kenya, female, 20-24

Certainly these doctors are not trained to deal with these cases. When someone presents with something like this, they find it strange and it shows on their faces and it feels as if you are saying or doing something grave. You could feel the hatred.

IDI, Egypt, street youth

There are no guidance workshops targeted at young people. Nurses sometimes do not want to listen to young people. They judge us and ask why are you sleeping with men when you are not married, and they also discuss us with people they know in the community. For example, if you went to the clinic because you had STI, everyone in the community will know that and sometimes even your family.

IDI with female PLHA, South Africa

Young people's experiences with existing HIV programs and services (except for ART services) were quite mixed, although they were more negative for MARPs who generally felt discriminated against by care providers.

It is a very big challenge...there is stigma. They will ask you where is your man, and you do not have a man so you are chased away.

IDI with female PLHA, Uganda

In our country...homosexuality is illegal, so...every hospital or public clinic, anyplace you go to you find that they are neglected or made to look inferior.

FGD, Uganda, female 20-24

Yeah and I got sexual infection, I survived. I went to the council facility in Mombasa. The female provider I got there slapped me and told me that they do not treat such diseases and that if I had gone for anal sex I should Jipange [know where to seek for treatment]. Then after a short while I learned about KEMRI, where I was treated for the first time.

IDI with MSM, Kenya

Health workers do not understand what our needs are. They are not adequately trained to provide services to LGBTI.

IDI with LGBTI, South Africa 
In a bid to obtain confidential services, some young people resort to self-medication or decide to seek services in faraway locations.

Mostly...first of all, they will go to pharmacies because some of these ailments or infections are embarrassing. So, they will go and describe whatever they are feeling probably to a pharmacist. Sometimes it is not even a nearby pharmacist, so that they don't have to meet with that person ever again, and where the story might leak.

IDI with married female adolescent, Kenya

It is impossible to go for such service in my locality because I don't want anyone to know this information.

IDI with MSM aged 20-24, Egypt

It also emerged that the setup of HIV services discouraged many young people from accessing services. Respondents noted that HIV service points in most facilities are located away from other general services, making them unsuitable for those seeking HIV services because they would be easily identified and labeled HIV-positive.

Another issue is the fact that services for HIV-positive people are separated from other services. Even their clinic cards are a different color (white). So everyone in the community knows that if you carry a white clinic card or you go to a designated area for HIV-positive people, you are indeed HIV-positive.

IDI with female PLHA, South Africa

I wouldn't feel comfortable to enter such places because of what people would be thinking or saying; this is a kind of disease nobody wants to be associated with, because the moment you are known to have it, people's interpretation of you would be negative.

IDI with male IDU, Nigeria

Fikiria Jamii deals with TB, HIV...and if anybody sees you entering that hospital, there is no other assumption but that you are positive.

FGD, Kenya, male 20-24

The youth face SRH problems that are also linked to livelihood struggles. Economically disadvantaged youth were said to be at risk of being lured into intergenerational relationships and/or risky sexual behavior for financial and material gain.

These days boys are not selective. They...have this tendency of falling in love with "sweet mummies" because they have money, so if he is told to stay with her he does accept. He doesn't know maybe she is infected or what.

FGD, Kenya, female 15-19

The ladies will notice trends, fashion. They need to eat fries and go swimming...and if you can afford some fifty shillings for chips, one hundred shillings to take her swimming. The next thing that happens is negotiations on the prices, then we have sex and she conceives.... So they may be hearing that they should use the "c" word (condoms and contraceptives), but probably it hasn't rang a bell.... We may talk about them here, but they never get serious about them.

IDI with male PLHA, Kenya 
I see it as a problem in this way. When these young girls go and engage themselves with older men, they are trying to get money like she has said, okay. But then this money will not be given to them on a silver plate. This guy will ask her, I have to sleep with you first, so probably she may go away with sexual infections, and in that way she is affected.

FGD, Uganda, female 18-24

\section{Macrosocial Service-delivery-level/Institutional Responses}

Across all countries, institutional responses to HIV and SRH education and appropriate access to youthfriendly services, especially for the most vulnerable groups of youth, continue to fall short of the needs and expectations of young people. This is true on both the community and national level.

Although, as previously discussed, there are obvious gaps in young people's knowledge of HIV and SRH, which increases their vulnerabilities, access to necessary information is still being denied to young people. The failures of institutional responses in the study countries can be tied to the broader issue of denial and lack of openness about youth sexuality. According to most respondents, there is a general acknowledgement in society that young people are sexually active, however sex remains taboo and is barely discussed in most homes and schools. Some respondents mentioned that their societies still hold the view that if sex education is provided to young people, then they will behave immorally.

Well the society we are in now believes that young people will be sexually active if they are informed. They think is better that young people stay in the dark than be informed. Because informed on sexuality and bodily wise, young will be sexually active.

FGD, Nigeria, female 15-19

The obvious truth now is that every young person is sexually active, but the society does not expect you to be real. They shy away from the truth, endangering the lives of young people.

FGD, Nigeria, male 20-24

They do appreciate, but they don't come out openly to talk about this. They don't have the media to pass over this information.

FGD, Kenya, female 20-24

Because of these taboos, most parents fail to initiate discussions with their children about sex. Parents and other adult members of society were said to be uncomfortable discussing issues of sexuality with young people. A lot of parents seem to find talking about sex "embarrassing" or amounting to "bad manners," hence many ignore the subject or shy away from it. As a result, most young people alluded to accessing information from school, peers, siblings, or close relatives.

Some parents are also not very open to their children about these things...sometimes it's better to talk to a brother or a cousin.... In most cases, I get information from my friends. For example, you see something on television and you start talking about it with your friends. It's easier that way.

FGD, South Africa, female 20-24

Personally, my mother has never told me anything about my body. I always know them from school or seminars. I don't understand the reason she can't tell me.

FGD, Kenya, female 15-19 
Within the families, parents don't know how to live with their children teaching them about these issues. You may find a mother warning her daughter from being found with a man or just being cruel to her. You should just sit with her down and teach her about the effects, so she can follow the right direction....

FGD, Uganda, female 20-24

Some parents are also responsible to the extent that they do not want their children to participate in these kinds of activities, because they believe that this will encourage them to debauchery.

FGD, Senegal, female 20-24

In Senegal and parts of Nigeria, adult attitudes are strongly rooted in cultural and religious values. Hence, adults find it difficult to accept that young people are sexually active.

A girl who is not married yet, does not have the right to have sex. This is what is accepted by our culture.

FGD, Senegal, male 20-24

How would our society acknowledge that (young people can be sexually active), even if it's the reality? Young people engage in sex here and there, yet the society does not accept that.

FGD, Nigeria, female 20-24

Where sexuality education is provided, the information is inadequate. Some participants questioned the scope of information provided, given that information on sexuality is often presented in a negative light.

It is because, yes, I have been in a couple of youth programs and so these leaders of ours they are like sex is bad. They only show you the disadvantages. They will never say that this is the only good thing of it, and when you are like Jude who goes for one for the road, they are like Jude, beers are bad.

FGD, Uganda positive female 15-19

Participants stated that in primary and secondary schools, sexuality education only covers a narrow set of topics mostly limited to abstinence. It appears that topics on condom use, family planning, and HIV testing and counseling are not taught, yet participants viewed them as important in taking preventative action.

Yeah (laughs), but for now the government has refused. They don't entertain condom stories in school, but I think it's very important students should be taught the benefits of using condom, at least there will be no cases of early pregnancies and STIs.

FGD, Kenya, male 15-19

It is not in the school curriculum. I have never seen any school promoting the use of condoms or comfortably discussing sexual organs.

FGD, Nigeria, female 20-24

In Kenya, Nigeria, Senegal, and South Africa, youth reported that school programs at the secondary level addressed health, SRH, and HIV education. Although the strong emphasis was on abstinence, some additional topics on SRH and HIV are covered.

In secondary schools, it remains unclear whether topics related to HIV counseling and testing services, diagnosis and treatment of STIs, and sexual violence are taught, because there was no mention of them in the interviews or discussions. 
The issue they emphasize in secondary. What I have seen, okay they will emphasize abstinence mostly, faithfulness, and use of condom....

FGD, Uganda, female 15-19

Abstinence messages are being preached. There are societies/clubs in schools currently that discuss/promote SRH and HIV education. No condom message, but it is highlighted as one of the contraceptive.

FGD, Nigeria, female 15-19

That they (drugs) are harmful to our bodies. If you get used to them, you get addicted and you will not stop using them.

FGD, Kenya, male 15-19

Participants also felt that the reach of youth-focused programs was limited and some vulnerable groups of youth were not adequately involved in current youth-focused programming. The perception among participants across all countries was that there were few programs targeting out-of-school youth. Therefore, most out-of-school youth mainly obtained SRH and HIV information through community channels such as community outreach activities, peer education, and from attending seminars. However, participants from Nigeria and Uganda in particular felt that out-of-school youth were not as well-informed as their in-school counterparts regarding SRH and HIV.

Youth corps members conduct outreaches and other activities to out-of-school youths, especially in the north where people hardly go to school.

FGD, Nigeria, female 20-24

Usually in the communities, so once you drop out you...the youth rarely have those outreaches. It's only one program that I have always been seeing and I am still seeing it and I think I will always keep on seeing it. It's only Naguru teenage, it's the only one that comes out.

FGD, Uganda, female 20-24

Participants from across Kenya, Nigeria, South Africa, and Uganda mentioned that they were aware of existing programs for orphaned children. Such programs were said to offer a range of services including ARVs, treatment and care, food, and financial and material support. Most of these services are supported by NGOs, but it was also stated in Kenya, South Africa, and Uganda that the government was playing a notable role in providing similar services.

Yes, Lovelife GogoGetters, the Department of Social development has community caregivers that go to the community and provide support to child headed homes.

FGD, South Africa, female 20-24

The former GTZ...it is doing a good job of helping the orphans. Right now it is giving the ARVs to the HIV infected.

FGD, Uganda, female 20-24

There is the children's homes that are government sponsored, which mostly caters for those who might be living with HIV. Or the parents left them long time ago with the same.

FGD, Kenya, female 20-24

Yes, EVA has one of such program. They go into rural areas majorly to meeting with the orphans, and they know who and who.

FGD, Nigeria, female 20-24 
In Nigeria, because of pervasive stigma and discrimination, not all respondents were in agreement that orphans receive the necessary support they require.

There is no support for orphans, girls and boys infected by HIV/AIDS, because of the stigma and discrimination. People withdraw their children/wards from the school.

FGD, Nigeria, female 15-19

PLHIV are being quarantined. There are some kinds of support, but do not know if they are in existence.

FGD, Nigeria, female, PLHA

Different programs for street children were also said to exist in Kenya and Uganda. The programs are mainly focused on rehabilitation.

The name of that organization I don't know since I just watched it in news. It was taking street boys; it has a branch in Bahati, they took street boys to school then they are made to live together with provision of everything and they have sponsors. But I don't know the name of the organization.

FGD, Kenya, male 20-24

Yeah, there are for example for the street kids Retruck Uganda. It is somewhere there in town, is it? I have forgotten the place, but I know it is there for the street children.

FGD, Uganda, female 15-19

Similar programs exist in Egypt, although street children's access to health services is severely constrained.

Last time I went to the hospital, but no one helps. They say where your father is, but sometimes the teacher from the organization comes with us.

IDI with male street adolescent, Egypt

In Nigeria and South Africa, no mention was made of programs targeting street youth besides the laws and policies on child labor, trafficking, and sex work that seemed familiar to respondents.

There is, like the Federal Government they've impose this child labor and prostitution, that is, how will I put it, prosecution against child labor and prostitution in Nigeria. But I don't know how effective it is...instead of pursuing prostitutes they're been sent to, and those street children, underage children, orphanage children who are being sent into the street for hawking instead of them tackling those issues. They left those issues and prostitution, and what they are pursuing is how to chase one poverty woman trying to make up his life by the roadside.

FGD, Nigeria, female $20-24$

Government clinics do not choose whether you are migrants or not. They give service to anyone that needs it for free of charge, but there are NGOs that would specialize in trafficked children or vulnerable children.

FGD, South Africa, female 15-19

On the whole, participants across the six countries did not have information on programs working with migrants, internally displaced persons, and domestic workers. For well-established epidemics (as in Kenya, South Africa, and Uganda), the growing population of perinatally infected adolescents though longacknowledged had attracted little or no systematic programmatic responses regarding SRH needs and concerns. It was clear from the qualitative inquiries that HIV-positive youth in the study countries continued to live in fear and secrecy and faced stigma and discrimination from family, friends, peers, and also at the facility level when seeking services. 
They can't sleep with us. They can't eat with us. Just stay in their room. One of the stigmas faced by the HIV-positive is the stigma from the family.

FGD, Nigeria, male 15-19

Like maybe you are walking and you pass somewhere; you will find the people discussing you. You will hear, "There he is, there he is, a carrier has just passed by. A carrier....

FGD, Kenya, female PLHA 15-19

I don't feel strong enough to tell my parents, because I am afraid of being rejected by my family and my surrounding.

IDI with male PLHA, Senegal

Yes, being talked about, telling the community about one's HIV status is common among us.

FGD, South Africa, female 15-19

My parents told me that I had sickle cell anemia.... Since I insisted in knowing more about the type of sickle cell anemia I had, and in front of their inability to give me a satisfactory answer, I decided to satisfy my curiosity by seeking information on the Internet. The symptoms I had made me suspect of AIDS. So, I decided to have the test that proved to be positive.

IDI with male PLHA, Senegal

In order to conceal their HIV status and to avoid stigma, many adolescent interviewees living with HIV also mentioned "going far" to seek medical services. For such youth, accessing services where they are known is risky.

So what do you think would happen if people in your locality knew that you are HIV-positive, then know things would go from bad to worse? Now that's why we go very far where people don't really know you.

IDI with LGBTI, Uganda

Most participants narrated how difficult it was for HIV-positive youth to access services. Some perinatally infected youth described negative provider attitude as something they worry about as they plan to visit health facilities. Respondents from Egypt and Senegal summed it up as follows:

In my case, I would not go to the CD4 lab anymore, even though I have to do this test every six months. There is one very cheeky provider there who spends her time harassing the patients.

IDI with PLHA, Senegal

Yes, when I went to the health center with one of my friends who had red spots, I was afraid that she have got AIDS. Once we asked them about AIDS, they started insulting us saying 'go to the person who did that to you to help you get treatment.' And they made scene in front of the whole center, so we left.

IDI with FSW, Egypt

Most of the youth easily identified various HIV and SRH services and where such services could be obtained, regardless of whether they had previously utilized the services. HCT services were said to be widely available by youth across the study countries. Both private and public facilities were identified as offering these services. SRH services were also reported to be available among a number of service providers. The same applied to PMTCT, HIV care and support services, ARV and family planning services.

Although it was acknowledged that many government facilities provided similar services, the majority of respondents were reluctant to seek services from those facilities because of fear of confidentiality breaches and unnecessary bureaucracy; instead they opted for NGO-based services or private facilities. 
However, in Senegal, youth reported a preference for public facilities because they were considered cheaper than the private ones

Almost all vulnerable young people said they seek help from public facilities when they are sick, because they are more affordable.

FGD, Senegal, male 20-24

Respondents also revealed that access to these private health providers was limited to groups of young people who are financially stable.

Yeah, I think those who are capable who have the money...they prefer the private, and those who are vulnerable, they will prefer the NGOs.

FGD, Uganda, female 15-19

In Egypt, young MSM and sex workers mentioned accessing services in private health facilities.

...As for me, I go to private clinics because it is better and more trusted instead of being humiliated if I went to the government clinic. If anyone is injured or will do an operation, they will stitch without giving any attention or being concerned, but in private hospitals, they give more care.

IDI with MSM, Egypt

I go to private hospitals because when people go to public hospitals they don't take care of them. Anyone who doesn't have money of course goes to the public hospital.

IDI with FSW, Egypt

\section{Policy Responses}

Across all study countries, a few youth-specific policy provisions exist and they are generally not followed through with adequate resourcing (funding, personnel, infrastructure, and supplies) of programs and services, especially for rural and poor urban youth, out-of-school youth, and young MARPs.

Interviews with key stakeholders and program managers reveal that a few high-quality SRH and HIV policies exist for youth. According to the respondents, the concern is more on commitment in implementing the policies. Many stakeholders mentioned that there is laxity in implementation and misappropriation of funds, which undermines implementation of youth programs. Some key informant interview respondents made the following observations:

Okay, let me start with the government. Their commitment is good, but I think they are very good in policy, very good in frameworks, very sound, they are very sound but in terms of implementation I know there is a lot to be done.

KII, Kenya

Youth aspects are generally neglected in South Africa. We have done a lot of research on youth behavior and HIV in this country, but the recommendations are not implemented. Issues that are recommended by previous research are not implemented. We do research and call senior people to disseminate the findings, but nothing will happen to respond to any gaps or recommendations mentioned. The research is supposed to help us develop strategies, but we do not do that. We have designed all the good tools, some of which are meant for monitoring and evaluation, but most of them are not evidence based. Donors depend on us; if we tell them what the priority is, they will go according to that.

KII, South Africa 
What I can say is at a country level the policymakers, for example the members of parliament, are very committed. Some are very committed, but when you come to like the executive, who are some of the decisionmakers on the resources of this country, they are not committed at all. So you find that at a committee level, for example a social service committee, they can say we need budget to be increased, but the ministry of finance says no money, then the president who is the final decisionmaker is not giving health a priority.

KII, Uganda

I think the level of commitment to women and youth issues is low, maybe because of other pressing needs and conflicting priorities...also because of limited funding.

$$
\text { KII, Egypt }
$$

Across the continent, there are loud policy silences and/or hostility regarding MARPs in general and young MARPs in particular, especially in Egypt and Uganda. In Egypt, implementing HIV programs among specific population groups is challenging given that funding for HIV programs passes through the government, which disburses funds to implementing organizations. This was viewed as a barrier in providing services among population groups engaging in unlawful practices:

Some NGOS are denied funds because they work with population...that the government does not approve of. Also, no NGO can provide AIDS medication. Even the Global Fund, with the new regulations will make it even difficult for the Egyptian government to get funds.

$$
\text { KII, Egypt }
$$

Unfortunately, most of the funding goes to raising awareness of the general population not among MARPs.

$$
\text { KII, Egypt }
$$

Lack of political will and subscription to traditional cultural norms were also viewed as impediments to implementation of youth-friendly HIV and SRH laws and policies.

As of now, some of the prevention programs that need to be implemented are not being implemented because policymakers are reluctant to take actions due to their beliefs. Taking action may pull down their political careers (e.g., talking about condoms, the same-sex bill); how policymakers discussed it was completely oblivious to international regulations. Programs also need to target policymakers to find out why they react that way.

KII, Nigeria

Local officials prefer to direct resources toward activities which give them more visibility, i.e., including sports activities such as traditional wrestling.

KII, Senegal

Egypt, in particular, was said to be facing a unique set of challenges. Other than the country's laws that criminalize sex work and same-sex practices, social values, cultural norms, and religion were said to be too deeply entrenched thereby standing in the way of implementing some SRH and HIV programs.

I think there is a problem with the policies because criminalization stands in the way of interventions for prevention or treatment...also social values and cultural norms.... We need a legislation or community dialogue to discuss AIDS as a national problem, and people who are working on HIV are not doing something against the law or religion or are promoting vice.... The whole society should understand that. 
In Senegal, however, it was reported that there was a strong commitment toward youth matters from the government and other donor agencies. This political will and commitment of the State is confirmed through the institutional measures.

Concerning the budget-line allocation for the purchase of antiretroviral (ARV) medicines...and free testing, there is a state directive which requires government ministries to make budgetary provisions for their response to HIV....

KII, Senegal

In general, the external donor community was perceived to be committed in funding youth programs, but the problems mentioned were a declining global economy and donor fatigue that are seen to be negatively affecting the current funding stream.

You see the support we have been getting from the Global Fund is not very predictable in last two years. The funding has declined seriously. Donors are not respecting their commitments, so you find that funding that has been channeled for HIV/AIDS is not really meeting the target.

KII, Uganda

My fear right now is a bit of fatigue within the donor world in the issues of HIV/AIDS. I know Global Fund, in terms of some of its strategies, they are actually not really funding not only for Kenya but even globally. Yeah, so when there is donor fatigue we also need to know how we address that issue.

KII, Kenya

Well, what I can say here is one of the factors is economic crisis. It has hit the world so seriously so you find that countries are struggling to sort out their home problems before they can look at sorting the global problem. For example, the case of the Global Fund. You look at what has happened in Greece, what has happened in Italy and other countries in Europe and America. So they are settling their economies first before they can be in position to inject money into other economies, for example for supporting the health sector.

KII, Uganda

\section{YOUTH INVOLVEMENT IN PROGRAM IMPLEMENTATION AND SERVICE DELIVERY}

It was clear from the narratives that participation by young people in different stages of SRH and HIV programming (design, implementation, and evaluation) is low and rarely goes beyond planning-stage consultations and provision of peer education/counseling.

No, no one had asked about our opinion. Our opinion was not taken or used in legislation. Also, they never asked us for our opinions or help in programs inside the association. They just asked us to tell our neighbors and there will be no problem.

IDI with married adolescent, Egypt

They (the government) set up laws or programs with themselves. I didn't meet anybody who has taken my opinion before; I didn't meet even anyone else whose opinion was sought. They only asked us at the election time who we shall we vote for.

IDI with married adolescent, Egypt

The involvement is not at all the stages. You realized that you been involved in the implementation, but at other stages no. I don't know I should call it a failure.

FGD, Kenya 
Youth in this area are not exposed to the development and delivery of HIV-and SRH-related programs.

IDI with youth peer educator, South Africa

I have only been a beneficiary from the LoveLife programs. They have peer educators, call Ground Breakers, who run workshops in schools and communities, and this has been benefiting a lot of young people where I live.

IDI, OVC, South Africa

Moreover, according to the respondents' narratives from the FGDs and IDIs, and with the exception of South Africa, the level of direct participation of young MARPs in policy consultation and program development is close to zero, especially for sex workers and IDUs. Overall, the lack of youth involvement is a major concern to young people, who feel that this is a serious gap in the system.

I think it's a mistake not to involve youth in program development, because if we want to heal a wound, you must go where it hurts. If the programs are developed at the top level only by adults, they may be rejected by the youth. Youth know what they experience, and what they want, and I think involving them would make the fight more effective.

FGD, Senegal, male 15-19

The government doesn't consult with youth in the laws that it enforces on them; they see what they think is right and they do it. It would be preferred, of course, if they sat with the youth and took their point of view and listened to their needs. And it is important that they take them from many areas and different governorates.

IDI, FSW, Egypt

\section{KEY INSTITUTIONAL ACTORS IN THE RESPONSE TO YOUTH VULNERABILITY TO HIV/AIDS}

The qualitative inquiries conducted across countries assisted the identification of key institutional stakeholders who work on youth HIV-related issues in each country (Table 12). 


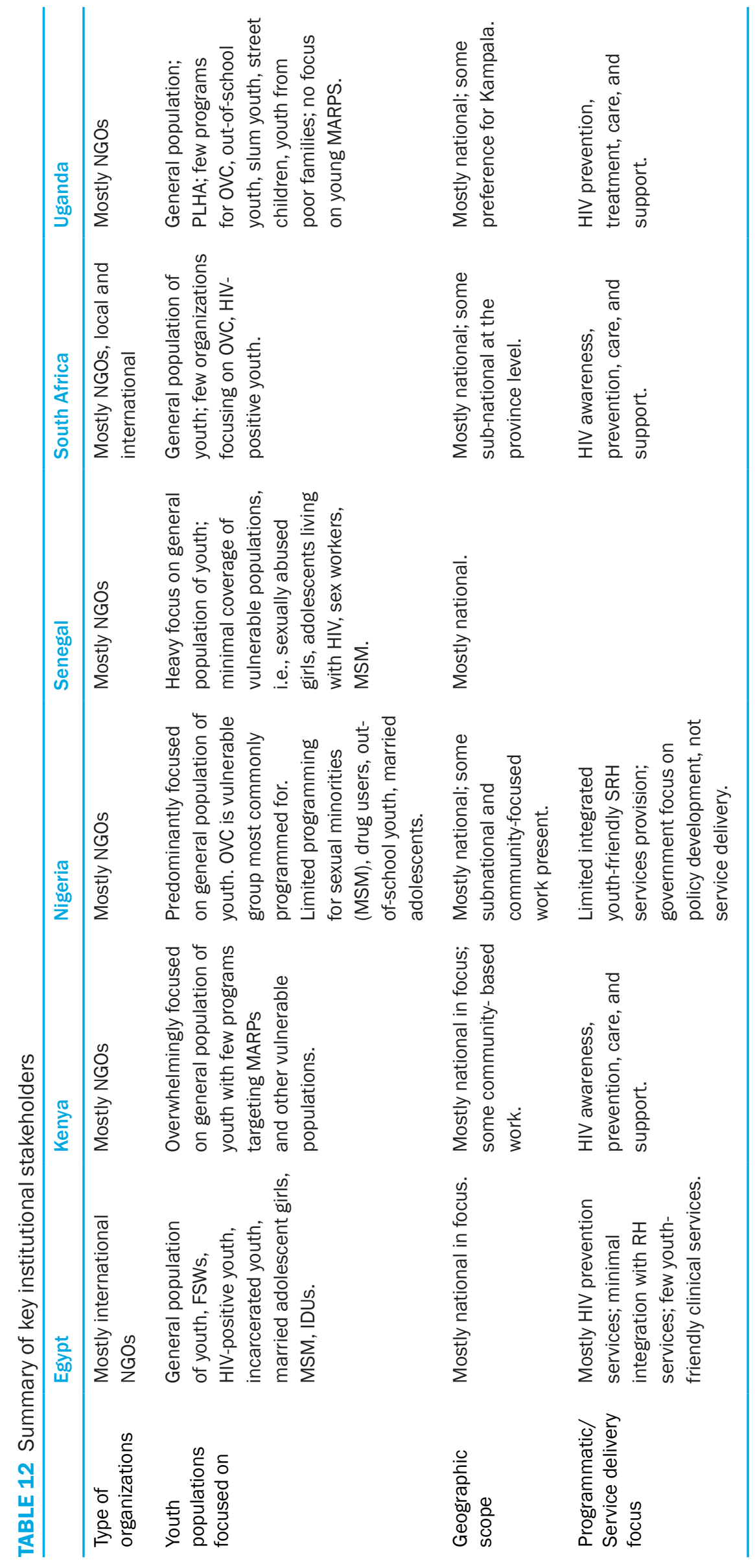


NGOs (local and international) dominate the lists of institutions thought to be most actively engaged in youthcentered HIV programs and services across all countries. In fact, NGOs and faith-based institutions were among the frequently mentioned and preferred service providers that seem to provide high-quality, youthfriendly SRH and HIV services.

They (NGO facilities) are very much accessible and then they don't have bureaucracy in giving out information. They usually do their thing openly other than in the government sector where it is like you want to fix them with the information that you want other than to spread them to other people that it can assist.

FGD, Kenya, male 20-24

NGOs are preferred because of confidentiality.... Some young people go to public clinics away from their homes so that no one must find out why they went to the clinic.

FGD, South Africa, female 15-19

Youth interviewed also see the NGO sector as operating independently without support from the government and perceived these organizations as being vibrant and more visible when it comes to implementation of $\mathrm{SRH} / \mathrm{HIV}$ policies.

(Policies) are only promoted by nongovernmental organization...but for the government, I think they still need a lot of time to work on these laws.

FGD, Uganda, female 20-24

This insight raises questions on the coverage, ownership, and sustainability of these services, because these organizations are wholly external-donor funded (excluding South Africa) as voiced by key informants:

As far as I know, more than 50 percent of funds are coming from government resources. However, the Global Fund is the main funding source of HIV programs, and without this money we would see a huge collapse of the program.

$$
\text { KII, Egypt }
$$

According to preliminary results from the first National AIDS Spending Assessment in 2011, about 10 percent of funding is estimated to come from public sources, 22 percent from private sources (largely households), and 67 percent from external sources.

KII, Uganda

Funding for HIV/AIDS in Nigeria is mainly from international donors. CSOs have no choice but to conform to donor-driven agendas, which may not necessarily solve immediate community needs.

KII, Nigeria

Table 13 summarizes the proportion of HIV funding allocation in the six focal countries. 
TABLE 13 Proportion of HIV funding allocation in the six focal countries

\begin{tabular}{|c|c|c|c|}
\hline Country & Government & International Donors & Private Sector \\
\hline Egypt & $\begin{array}{l}\text { Contributes about half of HIV } \\
\text { funding. }\end{array}$ & $\begin{array}{l}\text { Contributes about half of HIV } \\
\text { funding. } \\
\text { Mainly channeled through } \\
\text { the government. } \\
\text { Global Fund and Ford } \\
\text { Foundation are the major } \\
\text { donors; WHO was also } \\
\text { mentioned. }\end{array}$ & $\begin{array}{l}\text { No available information on } \\
\text { private-sector funding. }\end{array}$ \\
\hline Kenya & $\begin{array}{l}\text { Contributes part of HIV funding, but } \\
\text { is significantly low compared with } \\
\text { international donors. }\end{array}$ & $\begin{array}{l}\text { Main contributors to HIV } \\
\text { funding. } \\
\text { Donors mentioned include } \\
\text { Global Fund, PEPFAR. }\end{array}$ & $\begin{array}{l}\text { Plays a supportive role, i.e., } \\
\text { provision of some products } \\
\text { and services. }\end{array}$ \\
\hline Nigeria & Not a significant contributor. & $\begin{array}{l}\text { Main source of funding for } \\
\text { HIV. } \\
\text { Donors mentioned include } \\
\text { DFID, Global Fund, PEPFAR, } \\
\text { and World Bank. }\end{array}$ & $\begin{array}{l}\text { Limited information on } \\
\text { private-sector contribution. }\end{array}$ \\
\hline Senegal & $\begin{array}{l}\text { Contributes about } 5 \text { percent of total } \\
\text { funding for HIV intervention. }\end{array}$ & $\begin{array}{l}\text { Reported to contribute } \\
\text { about } 95 \text { percent of funding } \\
\text { through Global Fund. }\end{array}$ & $\begin{array}{l}\text { No information provided on } \\
\text { funding from private sources. }\end{array}$ \\
\hline South Africa & $\begin{array}{l}\text { Significant contributor to HIV } \\
\text { funding. }\end{array}$ & $\begin{array}{l}\text { A major source of funding } \\
\text { for HIV. } \\
\text { Donors mentioned include } \\
\text { CDC and PEPFAR. }\end{array}$ & $\begin{array}{l}\text { Contributes through } \\
\text { corporate social } \\
\text { responsibility programs. } \\
\text { Contributes through } \\
\text { workplace policies and } \\
\text { programs. }\end{array}$ \\
\hline Uganda & $\begin{array}{l}\text { Contributes about a third of the } \\
\text { funding for HIV. }\end{array}$ & $\begin{array}{l}\text { Main contributors. } \\
\text { Donors mentioned include } \\
\text { DANIDA, DFID, USAID. }\end{array}$ & $\begin{array}{l}\text { Does not have a significant } \\
\text { input in HIV funding. }\end{array}$ \\
\hline
\end{tabular}

Source: KIls with 84 policymakers and program managers across the six countries. 


\section{Chapter 6 \\ Conclusion and Recommendations}

\section{OVERVIEW OF KEY FINDINGS}

Legal and Policy Issues in Youth Vulnerabilities to HIV and Sexual Health Challenges

- Conflicting provisions under overlapping legal systems-customary, statutory/civil, and religious-engender violations regarding child marriage, age of consent, access to SRH information, etc.

- Lack of national adoption and adaptation or incomplete domestication of key international and regional protocols, e.g., CEDAW, Maputo Declaration, limits opportunities for youth-focused HIV policies and programs across the focal countries.

- Nonprovision for marital rape except in Kenya and South Africa represents a double jeopardy for married adolescents as they face heightened risk of HIV infection by often being married to much older sexually experienced men who frequently force them to have sex-and restrictions on access to abortion services (except for South Africa) for adolescent girls is the norm.

- Progressive laws and policies on AIDS-related stigma and discrimination exist (except in Egypt), but poor enforcement is prevalent in all six countries.

- Criminalization of sex work (except in Senegal) and same-sex relations (except in South Africa) acts as major barrier to efforts to address the HIV/SRH needs of young MARPs.

- National AIDS policies and strategic frameworks make few youth-specific and youth-centered provisions, although the situation is better with $\mathrm{RH}$ policies and strategic frameworks.

- Loud policy silence regarding very young adolescents and MARPs (sex workers, IDUs, MSM, and LGBTIs) is a key feature of existing national responses to HIV and SRH-related challenges.

\section{Patterns in Risk Behaviors and HIV-related Discrimination}

- Wide-ranging levels of current sexual activity among never-married youth were observed, with generally higher levels among males and modest rural-urban differentials, but with education level and being male most strongly predictive of this outcome among six associated factors.

- Multiple sexual partnerships among sexually active youth was found to be widespread but more prevalent among male youth, yet HIV prevalence among female youth is much higher, with some expressing greater fear of unwanted pregnancy than HIV infection.

- More than two-thirds of youth across all the age and locational groups report HIV nondiscriminatory attitudes, with education and household economic status being particularly strongly associated with this orientation.

- Livelihood struggles and unemployment feature prominently in youth narratives about sexual risk-taking.

\section{HIV Youth-focused Responses at the Individual, Institutional, and Policy Levels}

- Youth sexual-health-seeking behavior as gauged by their level of comprehensive HIV knowledge (>20 percent) and use of condoms during recent high-risk sex (roughly 25-75 percent) is relatively high but low 
in relation to uptake of HCT services (except in South Africa) with very large rural-urban differentials and notable male advantage except with regard to HCT uptake.

- Education turns out to be a very strong predictor of recent condom use and display of comprehensive knowledge of HIV.

- Service provider issues (attitudes, competence, etc.) are cited by many young respondents as major barriers to access to the very few available youth-friendly services.

- Youth experiences with existing HIV programs and services are mixed except for ARV services, although they are more negative among MARPs, who generally feel discriminated against by care providers.

- For well-established epidemics (in Kenya, South Africa, and Uganda), the long-acknowledged growing population of perinatally infected adolescents has attracted little or no systematic programmatic responses to their SRH needs and concerns.

- The few youth-specific policy provisions are generally not followed through with adequate resourcing (funding, personnel, infrastructure, and supplies) of programs and services, especially for rural and poor urban youth, out-of-school youth, and young MARPs.

- Youth participation in policy development and program implementation rarely goes beyond planning-stage consultations and provision of peer education/counseling, and with the exception of South Africa, the level of direct participation of young MARPs in policy consultation and program development is close to zero, especially for FSWs and IDUs.

- Huge public-private (NGO) sector gaps exist in the provision of quality youth-friendly services.

\section{DISCUSSION AND IMPLICATIONS}

This study highlights salient gaps and deficiencies in HIV prevention programming among youth in the six focal countries. While there may be country-specific differences in HIV prevalence, youth continue to remain a vulnerable group across countries. This is the first study, to our knowledge, that has evaluated similarities and differences in six epidemiologically, socioculturally, and legally different countries across the African continent.

Common to all countries is the association of higher education and higher socioeconomic status with risky sexual behaviors. Whereas it is imperative and a fundamental human right to provide quality education to all children and youth, it is also essential that they be provided with the skill-sets to better protect themselves during their budding sexuality. Furthermore, the imbalance between engagement in multiple sexual partnerships and condom use by sexually active youth raises concern for HIV prevention. Those with tertiary education were much more likely to engage in such high-risk sex, but only moderately more likely to use a condom during high-risk sex. This is a potent transmission bridge within youth and between youth and highrisk groups, thus perpetuating the HIV cycle between different populations.

The relatively high levels of sexual activity among African youth demonstrate the need for educating young people regarding safer sexual practices. This young population should have access to SRH services and youth-focused sexuality education that goes beyond abstinence-only messages. Prevention programs aimed at delaying sexual debut are important in the African context and should focus on both boys and girls and take into account the roles of poverty and sexual coercion in determining the sexual experiences of young men and women. Efforts to raise the awareness of parents, policymakers, and communities about the health and human rights implications of early marriage and sexual coercion among girls continue to be important and should be strengthened, as should interventions focusing on the financial empowerment of youth.

Another salient finding from this study is the lack of significant engagement of youth in policymaking, implementation, and HIV prevention programming. There is a large mismatch between what is developed for 
youth and what young people expect from the government. Also because of poor data use and dissemination at the policy level, key stakeholders responsible for formulating appropriate policies for youth lack the required evidence to design effective policies. This has multilevel impact, including advocating for necessary funding for youth-based programs.

Health-care providers, who are supposed to give succor to youth, become hostile and provide a concomitant health-care environment that is not sensitive to the needs of young people who require SRH services. Across all countries surveyed, respondents complained of being accused and judged of being immoral and denied treatment, sometimes with verbal and physical insult. There is, thus, a need to sensitize all cadres of health staff to be youth-friendly. Furthermore, health-care settings should be open, accessible, and welcoming to youth. Having a health-care facility less than five minutes walking distance does not translate to accessibility because proximity does not guarantee that services will be delivered to those who need them.

The relatively low use of condoms even in the context of high risk sex is especially notable among female youth. This gender difference may be due to gender norms that endorse female sexual passivity, hindering young women's access to essential SRH information and limiting their sexual negotiating power. The higher rates of condom use observed in South Africa which has long implemented vigorous prevention efforts that include condom messaging and distribution aimed at youth indicates the way to go for other focal countries on this score.

Comprehensive knowledge of HIV remains poor and is even poorer in rural areas. While this study did not evaluate any method of disseminating HIV knowledge, the low levels recorded in most countries raise cause for alarm. The health-belief mode ${ }^{33}$ is founded on the principle that there is a relationship between beliefs, attitudes, and behavior. Knowledge influences beliefs and perceptions and this fact has been key in HIV prevention programs focusing on improving HIV knowledge. However, with reference to the UNAIDS business case for youth, ${ }^{34}$ where at least 80 percent of young people in and out of school are expected to have comprehensive HIV knowledge, the data show that a lot of work still needs to be done to achieve this target.

\section{RECOMMENDATIONS}

Based on the findings of this study, the following strategic actions are hereby recommended:

- Improving sexual-health-seeking behaviors, especially uptake of HCT by male youth and condom use by female youth, through a combination of youth-empowering communication and poverty-reduction interventions is imperative.

- Evidence-based advocacy needs to be targeted at policymakers and donors to drive greater attention to the youth dimensions of the HIV epidemic, especially in relation to neglected but needy categories of youth.

- Innovative operations research is called for to better understand how to increase the meaningful involvement of young people in the conception, planning, and implementation of SRH and HIV/AIDS policies and programs.

- Efforts to promote the mainstreaming of youth-friendly SRH and HIV services are required given the challenges of scaling up and sustaining the few model standalone services provided largely by NGOs.

- Systematic domestication of key international regional protocols to align to individual country contexts needs to be advocated for aggressively.

- Alignment of civil, religious, and customary laws to ensure laws and policies are not contradictory needs to be fully explored.

\footnotetext{
${ }^{33}$ Azjen, I. and M. Fishbein. 1980. Understanding and Predicting Social Behavior. Englewood Cliffs, NJ: Prentice Hall.

${ }^{34}$ UNAIDS. 2010. "We can empower young people to protect themselves from HIV." Joint action for results, UNAIDS outcome framework: Business case 2009-2011." Geneva: UNAIDS.
} 
- The effective implementation of youth-specific laws and policies remains a challenge requiring multisectoral and multilevel actions, including increased funding.

- National AIDS coordinating agencies must live up to their oversight function in ensuring that young people are not neglected in national HIV policies and programs.

- Governments need to increase funding and demonstrate ownership and sustainability of youth-based HIV programs. 


\section{Bibliography}

Adedimeji, A.A, F.O. Omololu, and O. Odutolu. 2007. "HIV risk perception and constraints to protective behaviour among young slum dwellers in Ibadan, Nigeria," Journal of Health, Population and Nutrition 25(2): 146-157.

Ajuwon, A.J., F.O. Fawole, and K.O. Osungbade. 2011. "Experience and perpetration of violent behaviours among secondary school students in Ibadan, Nigeria," Sierra Leone Journal of Biomedical Research 3(1): 27-35.

Bamidele, J.O., O.L. Abodunrin, and W.O. Adebimpe. 2009. "Sexual behaviour and risk of HIV/AIDS among adolescents in public secondary schools in Osogbo, Osun State, Nigeria," International Journal of Adolescent Medicine and Health 21(3): 387-94.

Biddlecom et al. 2007. "Protecting the next generation in sub-Saharan Africa: Learning from adolescents to prevent HIV and unintended pregnancy." New York: AGI.

De Bruyn, M. 2000. "Gender, Adolescents, and the HIV/AIDS Epidemic: The Need for Comprehensive Sexual and Reproductive Health Responses." Expert group meeting on "The HIV/AIDS pandemic and its gender implications." 13-17 November. Windhoek, Namibia.

Harrison, A. et a.. 2005. "Early sexual debut among young men in rural South Africa: Heightened vulnerability to sexual risk," Sexually Transmitted Infections 81: 259-261.

Higgins, J.A., S. Hoffman, and S.L Dworkin. 2010. “Rethinking gender, heterosexual men, and women's vulnerability to HIV/AIDS," American Journal of Public Health 100(3): 435-445.

Human Sciences Research Council. 2009. "South African National HIV prevalence, incidence, behavior and communication survey, 2008: A turning tide among teenagers?” Cape Town: HSRC.

Ikechebelu, I.J., G.O. Udigwe, N. Ikechebelu, L.C. Imoh. 2006. “The knowledge, attitude and practice of voluntary counselling and testing (VCT) for HIV/AIDS among undergraduates in a polytechnic in Southeast, Nigeria," Nigerian Journal of Medicine 15(3): 245-249.

Iyaniwura, C.A., O.J. Daniel, and O.O. Adelowo. 2007. "Attitude of youths to sexual abstinence as a strategy for HIV prevention," Nigeria Medical Practitioner 52(2): 33-37.

Kabiru, C.W., D. Beguy, J. Crichton, and E.M. Zulu. 2011. "HIV/AIDS among youth in urban informal (slum) settlements in Kenya: What are the correlates of and motivations for HIV testing?" BMC Public Health 11: 685.

McCauley, A.P. 2004. "Equitable access to HIV counseling and testing for youth in developing countries: A review of current practice," Horizons Report. Washington, DC: Population Council.

Mumtaz, G., N. Hilmi, W. McFarland, R.L. Kaplan, F.A. Akala, et al. 2011. "Are HIV epidemics among men who have sex with men emerging in the Middle East and North Africa? A systematic review and data synthesis," PLoS Med 8(8): e1000444. doi:10.1371/journal.pmed.1000444.

Ndiaye, S. and M. Ayad. 2006. Enquete Demographique et de Sante Senegal 2005. Dakar: Ministere de la Sante and Calverton, MD: ORC Macro. 
Neema, S., N. Musisi, and R. Kibombo. 2004. "Adolescent sexual and reproductive health in Uganda: A synthesis of research evidence. Occasional Report No. 14.” New York: Alan Guttmacher Institute.

Oomman et al. 2007. "Following the funding for HIV/AIDS: A comparative analysis of the funding practices of PEPFAR, the Global Fund and World Bank MAP in Mozambique, Uganda and Zambia." Washington, DC: Center for Global Development.

Owolabi, A. et al. 2005. "Sexual behaviour of secondary school adolescents in Ilesa, Nigeria: Implications for the spread of STIs including HIV/AIDS," Journal of Obstetrics and Gynaecology 25(2): 174-178.

Parker, W. et al. 2007. "Concurrent sexual partnerships amongst young adults in South Africa: Challenges for HIV prevention communication.” Johannesburg: CADRE.

Population Council and UNFPA. 2003. "Adolescent and youth sexual and reproductive health: Charting directions for a second generation of programming." New York: Population Council.

QSR Nvivo 9 Software (International Pty 2007, Australia).

Santis et al. 2007. “Involving young people in efforts to combat HIV and AIDS in Africa." Washington, DC: EDC.

Sedlock. 2000. "Reaching the youngest adolescents with reproductive health programs. In FOCUS Series." Washington, DC: Focus on Young Adults.

Smith et al. 2009. "Men who have sex with men and HIV in sub-Saharan Africa," Lancet 374: 416-22.

UNAIDS. 2002. “Sex work and HIV/AIDS: Technical update.” Geneva: UNAIDS.

—. 2009. "2009 Report on the global AIDS epidemic." Geneva: UNAIDS.

2010. "Trends in HIV prevalence and sexual behaviour among young people aged 15-24 years in countries most affected by HIV." Geneva: UNAIDS.

- 2011. "Securing the future today: Synthesis of strategic information on HIV and young people." Geneva: UNAIDS.

UNICEF. 2011. “Opportunity in crisis: Preventing HIV from early adolescence to young adulthood." New York: UNICEF.

Varga, C.A. 2001. "The forgotten fifty percent: A review of sexual and reproductive health research and programs focused on boys and young men in sub-Saharan Africa," African Journal of Reproductive Health 5(3): 175-195.

World Bank. 2008. “The World Bank’s commitment to HIV/AIDS in Africa.” Washington, DC: World Bank.

Yahaya, L.A., A.A.G. Jimoh, and O.R. Balogun. 2010. "Factors hindering acceptance of HIV/AIDS voluntary counselling and testing (VCT) among youths in Kwara State, Nigeria," Journal of AIDS and HIV Research 2(7): 138-143. 


Population Council No. 16 Mafemi Crescent Abuja, Nigeria

Ideas. Evidence. Impact. 